\title{
The role of diversity in organizational resilience: a theoretical framework
}

\author{
Stephanie Duchek ${ }^{1}$ - Sebastian $\operatorname{Raetze}^{1}{ }_{(D)}$ \\ Ianina Scheuch ${ }^{1}$ (D)
}

Received: 24 May 2017 / Accepted: 4 January 2019/Published online: 11 January 2019

(C) The Author(s) 2019

\begin{abstract}
Organizations today operate in an increasingly complex and turbulent world in which unexpected events are omnipresent. Thus, they need to develop resilience capabilities to manage unexpected disruptions, maintain high performance, and even thrive and grow. In research, there are preliminary indications that diversity could play an important role in the development of resilience in organizations. However, although there are numerous studies on both resilience and diversity, the connection between the two constructs remains largely unexplored. Our paper aims to narrow this research gap by answering the following questions: What role does diversity play in the development of organizational resilience? What does this mean for resilience-enhancing diversity management? To answer these questions, we link existing research on elements of organizational resilience and outcomes of diversity in organizations. By developing a theoretical framework, formulating propositions, and discussing implications for further research, this paper provides a foundation for future empirical research. Moreover, it offers useful insights into the successful management of organizational resilience.
\end{abstract}

Keywords Organizational resilience $\cdot$ Resilience capabilities · Diversity · Resilience-enhancing diversity management

\section{Introduction}

Due to advancing globalization and the internationalization of business activities, firms operate in an increasingly complex and turbulent world in which unexpected events are omnipresent (Grote 2009; McCann et al. 2009). Political and legal

Sebastian Raetze

sebastian.raetze@tu-dresden.de

1 Faculty of Business and Economics, TU Dresden, 01062 Dresden, Germany 
changes, high market volatility, and global financial crises are only three examples of turbulence that may threaten a firm's survival. To be sustainably successful, firms need to develop organizational resilience, which can be defined as the ability to anticipate potential threats, to cope effectively with unexpected events, and to learn from these events in order to produce a dynamic capability that is directed toward facilitating organizational change (Duchek 2014). Resilience allows for effectively handling crises and can even be a source of competitive advantage (Hamel and Vaelikangas 2003; Sheffi 2005) and long-term success (Coutu 2002; Horne 1997).

To develop organizational resilience, firms require adequate resources that support the development of resilience capabilities such as financial reserves, redundancy, and positive relationships (e.g., Kendra and Wachtendorf 2003; Gittell et al. 2006; Välikangas and Romme 2013). There are preliminary indications that diversity also plays an important role in the development of resilience in organizations (see, e.g., Filatotchev and Toms 2003; Sutcliffe and Vogus 2003; Hong and Page 2004; Baral 2013). We understand diversity as "the distribution of personal attributes among interdependent members of a work unit" (Jackson et al. 2003 , p. 802). Work units may be organizational departments, groups, or teams of at least three people. Diversity research has demonstrated that diversity within these work units has an influence on organizational outcomes such as performance (see, e.g., Glick et al. 1993 or the recent review of Nishii et al. 2018). Accordingly, we suggest that diversity within work units can support the development of collective capabilities that underlie an organization's resilience.

While a large body of previous research addresses the effects of diversity on organizational and group performance (e.g., Horwitz and Horwitz 2007; van Knippenberg and Schippers 2007; van Knippenberg and Mell 2016; Srikanth et al. 2016; Guillaume et al. 2017), the possible association between diversity and resilience has remained largely unexplored. Using an example from the financial crisis of 2007, the need to research this relationship can be elucidated. In 2011, the International Monetary Fund (IMF) published a report that aimed to answer the question of why the organization failed to anticipate the crisis. The main reasons given were "a high degree of groupthink, intellectual capture, a general mindset that a major financial crisis in large advanced economies was unlikely, and incomplete analytical approaches" (International Monetary Fund 2011, p. 17). Various authors analyzed the factors leading to that failure and found a main cause in the leadership team at IMF, comprised mostly of men with strong socio-demographic backgrounds and similar life experiences and, therefore, lacking heterogeneity (e.g., Momani 2007; Wagner 2010; Seabrooke and Nilsson 2015). Although the IMF was not directly affected by the crisis, this example demonstrates that the relationship between an organization's anticipatory capacity and its work-unit diversity is a relevant topic in business practice. Nevertheless, it also indicates the importance of enhancing knowledge in that area to prevent unexpected events from becoming major crises. Hence, academic research about the relationship between diversity and resilience may provide interesting and useful insights into effective resilience management.

This paper aims to narrow the existing research gap by answering the following questions: (1) What role does diversity play in the development of organizational 
resilience? (2) What does this mean for resilience-enhancing diversity management? Our paper addresses these questions conceptually and uses quotes from interviews with diversity experts as illustration. First, we offer the theoretical background for both resilience and diversity in organizations. Second, we build on a process-based conceptualization of organizational resilience to examine the role of diversity in the development of organizational resilience. We develop a conceptual framework by linking the existing literature on elements of organizational resilience and outcomes of diversity within organizations. Our study shows how diversity in work units can enhance resilience capabilities that underlie three resilience process stages (anticipation, coping, and adaptation). Furthermore, as diversity does not offer positive outcomes per se, our study exemplifies the main components of resilienceenhancing diversity management, which can serve as a moderator for raising the resilience-enhancing potential of diversity. By formulating propositions, the paper contributes to future empirical research and provides useful insights into successful management of organizational resilience.

\section{Theoretical background}

\subsection{Previous research on organizational resilience}

\subsubsection{The resilience concept}

The resilience concept has a long tradition in various disciplines including material sciences, psychology, and ecology (see, e.g., Williams et al. 2017). Only recently has the concept gained increasing attention in organization and management research. Resilience is considered an essential success factor for organizations in unstable and uncertain times that allows them to cope with various kinds of disturbances from adverse developments to major crises (McCann et al. 2009). A resilient organizational system is able to respond successfully to any kind of disturbance and even thrive in spite of it (Lengnick-Hall et al. 2011; Linnenluecke 2017). Recent research agrees that organizational resilience is a complex, multifaceted, and multidimensional construct; however, the utilized notions and definitions of resilience vary greatly depending on the particular research context (Bhamra et al. 2011; Sawalha 2015; Linnenluecke 2017; Williams et al. 2017).

\subsubsection{Resilience process}

In organization and management research, resilience is used as an umbrella term for different perspectives and approaches (Burnard and Bhamra 2011; Duchek 2014, 2019; Linnenluecke 2017; Williams et al. 2017). Early studies in particular understand resilience as a result or an outcome that can only be described ex post (Boin and van Eeten 2013). From this perspective, resilience is often defined as the ability to recover and thus is limited to the phase following adverse events (Williams et al. 2017). More recently, resilience has been understood as a process that leads to resilient outcomes (see, e.g., Sutcliffe and Vogus 2003; Burnard and 
Bhamra 2011; Linnenluecke and Griffiths 2012; Duchek 2014, 2019; Williams et al. 2017). This process perspective points to "the dynamic nature of resilience as an interaction between the organization and the environment" (Williams et al. 2017, p. 20). As such, resilience means to effectively respond to adverse events not only after such events but before and during as well.

\subsubsection{Resilience process stages}

To date, only a few researchers have provided deeper insights into the resilience process (see, e.g., Linnenluecke and Griffiths 2012; Duchek 2014, 2019; Williams et al. 2017). Although the developed approaches vary widely in their main focus, their understanding of resilience, and their number of suggested process stages, they all understand resilience as a process that links resources with outcomes and they focus on discrete elements within this process. Furthermore, they share the assumption that resilience includes multiple iterations and develops from one crisis to the next.

Building on previous process approaches, we distinguish three resilience stages, each referring to a different time horizon (before, during, and after the occurrence of unexpected events) (Linnenluecke and Griffiths 2012; Duchek 2014, 2019; Williams et al. 2017). In greater detail, we divide the resilience process into: (1) the anticipation stage, (2) the coping stage, and (3) the adaptation stage.

(1) Anticipation refers to the period before adverse situations or crises occur. Thus far, only a few scholars have called for this proactive perspective on resilience (see, e.g., Kendra and Wachtendorf 2003; Somers 2009; Burnard and Bhamra 2011). For example, Somers (2009, p. 13) mentions that "resilience is more than mere survival; it involves identifying potential risks and taking proactive steps to ensure that an organization thrives in the face of adversity." This does not mean completely avoiding crises - this is not possible. Rather, it means to possess the capability to quickly identify signs of a crisis and react to them effectively. Anticipation comprises the ability to observe internal and external developments, to identify potential threats, and-to the extent possible-to prepare for unexpected events (Somers 2009; Teixeira and Werther 2013; Duchek 2014, 2019). (2) As it is impossible to anticipate all relevant future events (Lengnick-Hall and Beck 2005), organizations must also be able to cope effectively with unexpected situations. Coping generally refers to the development and implementation of solutions for a specific problem (Duchek 2014, 2019). (3) Adaptation, as the stage following the adverse event, goes beyond the restoration of organizational functionality and focuses particularly on the development of new capabilities (e.g., Lengnick-Hall and Beck 2005; Lengnick-Hall et al. 2011). In this sense, various scholars consider organizational resilience as a dynamic capability that allows organizations to actively adapt to new circumstances (see, e.g., Vogus and Sutcliffe 2007; LengnickHall et al. 2011).

In summary, organizational resilience can be defined as the ability to anticipate potential threats, to cope effectively with unexpected events, and to learn from these events in order to produce a dynamic capability that is directed toward facilitating organizational change. Different authors argue that this organizational ability can only be achieved collectively. They point to the important role of individual 
resources (e.g., Mallak 1998; Riolli and Savicki 2003; Lengnick-Hall et al. 2011; McCann and Selsky 2012; Shin et al. 2012) as well as team resources (e.g., Salanova et al. 2012; Carmeli et al. 2013) in organizational resilience. Consequently, to develop organizational resilience, it is necessary to consider an organization as a whole and to understand the behavior of its groups and units (Williams et al. 2017). This is particularly important for the role of diversity, a phenomenon that spans different levels within organizations.

\subsection{Previous research on diversity}

\subsubsection{Notion of diversity}

In the literature, the term diversity is seldom explicitly defined. Researchers use a variety of labels to refer to diversity, such as heterogeneity, variation, or inequality (Harrison and Klein 2007), and generally, it can be described as "the distribution of differences among the members of a unit with respect to a common attribute" (Harrison and Klein 2007, p. 1200). In the organizational context, diversity is characterized by the heterogeneity of members within organizational work units (e.g., Jackson et al. 2003). Work units may be organizational departments, groups, or teams of at least three people (Jackson et al. 2003) and may be situated at different organizational levels (e.g., top management teams or organizational project teams) (Milliken and Martins 1996). Building on previous research and current developments in diversity research, we use a generic understanding of diversity as any form that (work-group) diversity may take in an organizational setting.

\subsubsection{Dimensions of diversity}

The construct of diversity serves as an umbrella term for various dimensions of heterogeneity, e.g., gender, nationality, ethnic origin, religion or worldview, disability, age, sexual orientation, and identity (Triandis 2003). Previous studies attempted to organize these dimensions into meaningful categories. The most-noted categorization differentiates between observable (demographic, e.g., race or ethnic background, age, gender) and non-observable (cognitive, e.g., knowledge and expertise, skills, values) diversity (Tsui et al. 1992; Jackson et al. 1995; Milliken and Martins 1996). This distinction is particularly important since visible differences can lead to reactions based on prejudices and previous experiences. Another type of diversity that is particularly relevant in the organizational context is experiential diversity (e.g., education, professional background, industry experience) (Milliken and Martins 1996). Current societal developments-such as increasing globalization and the wave of refugees in Europe-have led to the increasing importance of cultural diversity (for an overview on the construct, see Cox 1994). However, it is difficult to focus on only one dimension of diversity since in work groups; various dimensions naturally coexist and influence each other. Therefore, previous research has already called for the integration of different dimensions instead of focusing on single dimensions (van Knippenberg and 
Schippers 2007). We follow this call and adopt the widely accepted "diluted" (Jackson et al. 2003) meaning of diversity without considering different diversity dimensions. We make distinctions only for illustration, when necessary.

\subsubsection{Diversity outcomes}

A large body of diversity research focuses on the effects of (work group) diversity on work-unit outcomes (e.g., Horwitz and Horwitz 2007; van Knippenberg and Schippers 2007; Srikanth et al. 2016) as well as organizational outcomes (e.g., see Glick et al. 1993; Nishii et al. 2018). Since this research shows mixed findings in terms of diversity outcomes, diversity is often called a double-edged sword (Milliken and Martins 1996). To explain the potential effects of diversity, two main theories can be considered: the information/decision-making perspective and the social-categorization perspective (for reviews, see Williams and O'Reilly 1998; van Knippenberg et al. 2004; Horwitz and Horwitz 2007; van Knippenberg and Schippers 2007; Jackson and Joshi 2011). Studies based on the information/ decision-making perspective suggest that diversity offers a broader knowledge base and a range of perspectives that, in turn, can positively influence problem-solving and decision-making (Williams and O'Reilly 1998; van Knippenberg and Schippers 2007). Negative effects are explained mainly by the social-categorization perspective, which contends that diversity limits within-unit integration and may, therefore, be considered a source of intergroup conflict (Horwitz and Horwitz 2007; van Knippenberg and Schippers 2007). Van Knippenberg et al.'s (2004) categorizationelaboration model integrates these two perspectives. They argue that every form of diversity triggers both-social categorizing (negative effects through intergroup bias) and elaboration of task-relevant information and perspectives (positive effects) - while the final effect on performance depends on different mediators and moderators (e.g., relational conflict, cohesion, commitment, task informational and decision requirements, or task motivation).

Consequently, it can be assumed that the positive effects of diversity on organizational outcomes must be raised by supporting organizational conditions that leverage the benefits of diversity and hinder social categorization (Ely and Thomas 2001). Only if diversity is valued and well managed can it help organizations to respond to current trends and achieve competitive advantages (Cox and Blake 1991; Gardenswartz and Rowe 1998; Thompson 2016). Accordingly, recent research has started to investigate contextual moderators of diversity at the team and organizational levels (see, e.g., van Knippenberg and Schippers 2007; Guillaume et al. 2017).

Despite extensive research on diversity outcomes, only a few scholars have highlighted the potential role of diversity for resilience in organizations (see, e.g., Sutcliffe and Vogus 2003; Blatt 2009; Gomes et al. 2014). These first studies mention only that diversity has the potential to promote the development of resilience but do not offer a systematic and holistic approach linking the two constructs. It is the aim of our paper to narrow this research gap. Building on previous diversity research, we focus on work-unit diversity within organizations 
and examine the direct connection between diversity and resilience as well as relevant moderators.

\section{The link between diversity and resilience in organizations: a theoretical framework and illustration}

In the following sections, we present our theoretical framework on potential links between diversity and resilience (see Fig. 1) as a result of the reunification of existing research on potential outcomes of diversity within organizations and existing research on the development of specific elements of organizational resilience. To substantiate our theoretical arguments, we use the results of a qualitative interview study with eleven diversity experts. These experts are diversity or HR managers in large, international, and listed companies that are located in Germany and are members of the German Diversity Charter.

In detail, we argue that diversity can play a central role for enhancing organizational resilience if it is well managed. Based on the broad understanding of diversity as any form of work-group diversity (see, e.g., Jackson et al. 2003) and a process-based understanding of resilience (e.g., Williams et al. 2017), we focus on how diversity might affect the three process stages of organizational resilience (anticipation, coping, and adaptation). We reason that diversity can lead to the development and improvement of specific capabilities that underlie these stages.

In the first part, we use the resilience process stages as a structuring framework and focus on those capabilities within each resilience stage (anticipation, coping, and adaptation) that are influenced by diversity. We explain what lies behind these capabilities and refer to findings from resilience as well as diversity research to clarify the role of diversity for the development of these elements of resilience (see main effects in Fig. 1; propositions 1-3). In the second part, we develop an approach for resilience-enhancing diversity management. As mentioned above, diversity is often described as a double-edged sword (e.g., Milliken and Martins 1996), and it is well known that its positive effects do not develop per se. There is a need for adequate diversity management to lift diversity to its full potential (see moderating effects in Fig. 1; propositions 4-6).

\subsection{Effects of diversity on organizational resilience capabilities}

Previous research has already suggested that diversity may play a pivotal role in organizational resilience (see, e.g., Sutcliffe and Vogus 2003; Blatt 2009; Gomes et al. 2014); however, little is known about how diversity can enhance an organization's resilience capabilities. Building on previous research on both resilience and diversity, we will discuss important effects of diversity on different resilience capabilities.

The basis for all identified diversity effects is the broader knowledge base associated with diverse work units (Sutcliffe and Vogus 2003). This means that diversity in organizational work units serves as a source of heterogeneous perspectives, different cognitive mindsets, and creativity (e.g., Cho 2006). It 


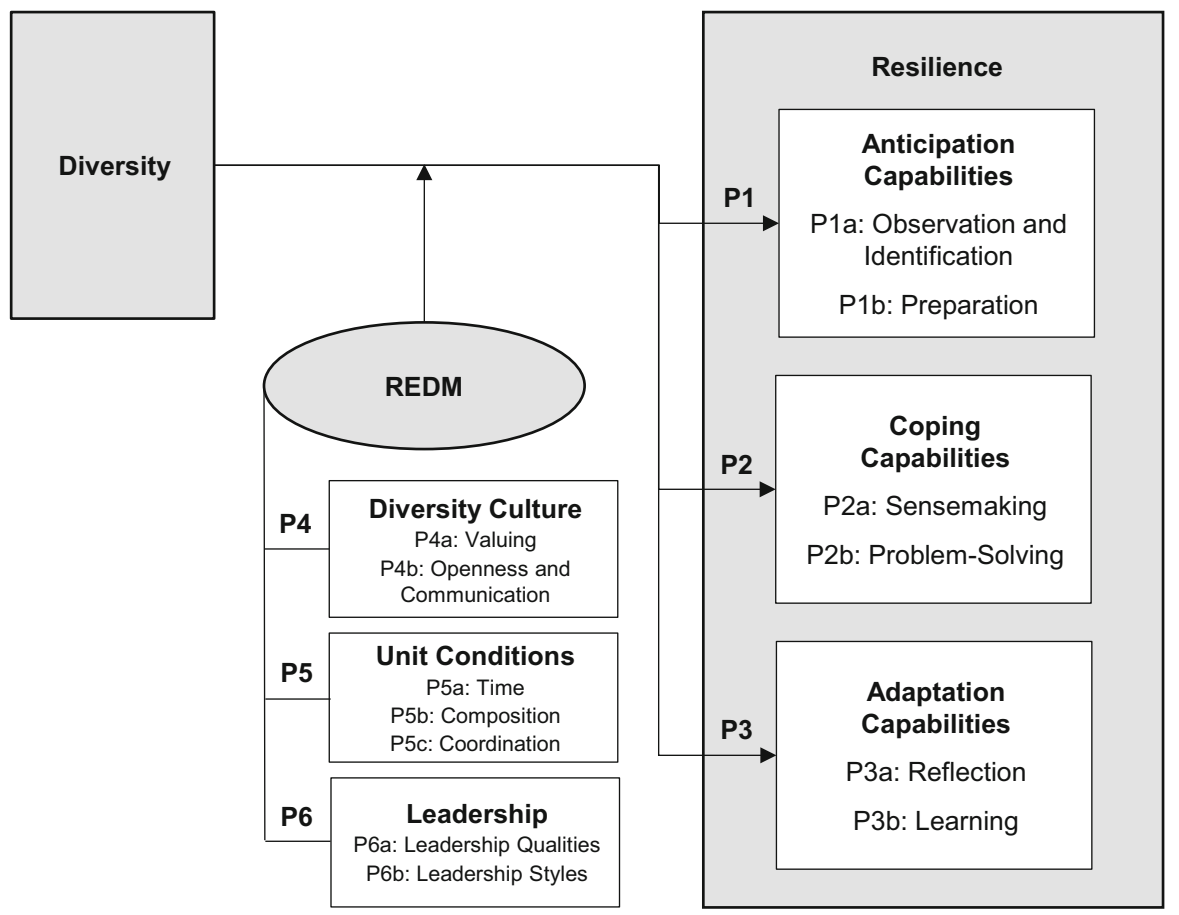

Fig. 1 Proposed effects of diversity on resilience capabilities

provides a larger pool of resources that can be helpful in dealing with unexpected problems (van Knippenberg and Schippers 2007). This is consistent with the idea of requisite variety and its important role in reducing errors (Weick 1987). Only if the members of organizational units themselves represent great variety are they able to deal with the varieties of the unit. If they lack variety, "they miss important information, their diagnoses are incomplete, and their remedies are short-sighted" (Weick 1987, p. 112). Our experts also agree that diverse work units can contribute to resilience by offering a broader knowledge base:

If I look at a team where I have, for example, someone who is a digital native, someone who is fully in technology, who has recently finished university, and I have, on the same team, someone who has been with us around forty years, then I simply have the entire range of knowledge there..... And that is something that enhances the resilience of the company (Expert $\mathrm{H}$ ).

In the following, we will show how this variety can affect the three process stages of organizational resilience (anticipation, coping, adaptation); more precisely, the specific capabilities that underlie these stages. The identified effects are formulated as propositions at the end of each section. 


\subsubsection{Anticipation capabilities}

From a process-based perspective, resilience is not limited to the stage after a critical event has occurred. It is situated earlier and includes capabilities that are useful prior to adversity (Williams et al. 2017). In this context, different authors refer to the anticipation phase of resilience (Burnard and Bhamra 2011; Duchek 2014, 2019, Williams et al. 2017). Anticipation describes the preventive aspects of resilience. It refers to the ability to detect critical developments within the firm or in its environment and to adapt proactively (Somers 2009; Ferreira et al. 2011; Teixeira and Werther 2013). Although this does not mean that resilient organizations can prevent every threatening event, anticipation capabilities help them to minimize negative consequences (Madni and Jackson 2009). For example, Somers (2009) argued that building resilience is a complex process that necessitates a greater ability to extract and interpret information from the constantly changing organizational environment. He introduces the concept of organizational resilience potential, defined as "...resilience that is not presently evident or realized" (Somers 2009, p. 13). Based on Mallak's (1998) work on latent resilience, he found evidence that organizational resilience potential could be operationalized by six factors (goaldirected solution seeking; risk avoidance; critical situational understanding; ability of team members to fill multiple roles; degree of reliance on information sources; and access to resources) that should be developed proactively before crises occur. Those preparation and planning activities build the foundation for effective responses to critical situations and thus realized resilience. Diversity may have positive effects on two elements of the anticipation stage: (1) the observation of the business environment and identification of relevant information and (2) the preparation for future developments.

(1) Observation and identification Diversity can be helpful for the observation of (external) developments and the identification of potential threatening developments. As early researchers in this field, Sutcliffe and Vogus (2003) argued that experientially diverse groups have a higher potential to perceive variations in their environment and to identify necessary adjustments because their heterogeneity enhances their capability to sense, register, and regulate complexity. Page (2014) asserted that cognitive diversity can improve predictive abilities and thus is particularly important in complex environments. Cognitive diversity produces different interpretations of signals, which, when aggregated, lead to more accurate collective predictions. Page also emphasized that diverse work units cannot reduce complexity or the number and extent of unforeseen events, but that a greater heterogeneity of ideas within people's heads "should lead to less collective surprise and therefore better preparation for the consequences" (Page 2014, p. 275).

Research on diverse top management teams (TMT) has shown that diversity allows for better environmental scanning and perception of complex environments. For example, the empirical study by Cho (2006) found that TMT with a higher magnitude of turnover in membership tended to have a broader scope of environmental scanning, both within and across different sectors, as such changes bring in new information sources and environmental scanning practices. Moreover, the author found that the teams' demographic heterogeneity positively moderated 
the association between executive turnover and environmental scanning. In her sample, teams that experienced significant turnover and thus became diverse in their functional experience, industry tenure, and educational background were especially better able to scan their external environments extensively, across a larger number of sectors and in greater depth. Moreover, we know from innovation literature that a firm's knowledge base has a significant influence on its ability to identify external knowledge (e.g., Cohen and Levinthal 1990) by defining the locus of the knowledge search (e.g., Rosenkopf and Nerkar 2001). The broader the knowledge base, the greater the amount of information that can be absorbed.

However, there are also indications that diversity may have negative effects. For example, Sutcliffe (1994) found that functional heterogeneity in top management teams has a negative influence on accuracy in noticing environmental changes. She explained that this may be the result of low levels of interaction that hinder deep analyses and the effective integration of perspectives. Consequently, Sutcliffe (1994) emphasized the important role of team communication and informationprocessing characteristics for positive diversity effects.

Our experts maintain that a heterogeneously assembled work unit can contribute to resilience by resulting in greater sensitivity and a more differentiated perception toward a cross-thematic spectrum of potential risks in the business environment. This refers to market potential and enables better recognition of special customer wishes and market developments as well as a wider perception of potential crises in general:

Well, we are very strong in this area: "How is the life of our clients shifting? What do our customers want?"... And I think that we can better recognize this because we have mixed teams that better reflect and know the market.... And if we do not reflect this in our teams, then we will probably miss both potential trends as well as risks (Expert F).

The more diverse a team is assembled, the more heterogeneous are... perceptions of trends and risks (Expert I).

I would say that if I have different approaches and perspectives, then I am more resilient in the first step because I have probably thought of more critical things (Expert $\mathrm{J})$.

(2) Preparation Diversity can also improve an organization's ability to prepare for unexpected events. Resilience researchers argue that organizations achieve resilience through preparation, taking into account that preparation does not refer to a specific event but rather helps to develop general capabilities, knowledge, and functions that are necessary for managing any kind of unexpected events (Wildavsky 1991; Kendra and Wachtendorf 2003).

Research points to proactive alignment as a specific form of preparation. For example, Teixeira and Werther (2013) argued that anticipatory innovation and its management form the foundation of a resilient organization. Such organizations anticipate the needs and desires of buyers and are able to adapt proactively"reacting to future changes before they happen" (Teixeira and Werther 2013, p. 335). Anticipatory innovation helps organizations to keep pace in fast-changing 
environments or even to be one step ahead of upcoming changes. In this context, diversity can be extremely helpful; it is believed to enhance innovation, resulting in better products and processes (Pregenzer 2014). Diversity research has demonstrated that diversity can lead to more creativity and innovation (Bantel and Jackson 1989; Cox 1991; Milliken et al. 2003). Innovation research also confirms that diversity is important for creativity in the new-product development process (e.g., Sarin and McDermott 2003; Haon et al. 2009; Hall and Ellis 2010; Aç1kgöz et al. 2016; Dayan et al. 2017). For instance, there is evidence that functional diversity may be beneficial for new-product development teams and that this relationship is especially strong under high project uncertainty (e.g., Açıkgöz et al. 2016; Dayan et al. 2017). Therefore, it can be assumed that diversity may help organizations to better prepare in complex settings. However, previous research has also highlighted the important role of moderating factors. For example, Haon et al. (2009) argued that familiarity among team members positively influences the relationship between diversity and the instrumental use of information, helping teams to transform diverse knowledge into new products or solutions. Other authors have referred to effective communication (Keller 2001) or to the role of team leaders (Sarin and McDermott 2003) as significant factors in increasing new-product development in cross-functional teams.

In summary, we contend that diverse firms are better able to proactively align and thus proactively adapt to potential crises. Our experts also mention that diversity can contribute to proactive alignment. In particular, they note that diversity improves the proactive development of innovations and new products. This helps organizations to be successful in the long term and, thereby, contributes to resilience:

By having diverse teams ..., we ideally employ a colorful mix [of people and abilities], which enables us to develop the right products that will be marketable for at least 10 years (Expert A).

We use diversity because we strongly believe that having diverse teams means having colorful and heterogeneous teams, new impulses can be set, and that new products can be developed. Diversity is the only way to stimulate innovation (Expert E).

Conclusion Overall, it becomes clear that, although diversity cannot ensure that organizations will anticipate every threat and will not necessarily reduce the number or extent of crisis events, diverse organizations may be better able to observe internal and external developments and identify potential risks, thereby assisting organizations in the identification of issues before they develop into major crises. Furthermore, diverse organizations are better equipped to adapt proactively. This means that diversity helps build a better basis of operations for forthcoming crises, thus developing a resilience potential (see, e.g., Somers 2009).

Proposition 1 Diversity positively influences the development of anticipation capabilities by improving (a) the observation and identification of critical changes within an organization's business environment and $(b)$ the preparation for future developments. 


\subsubsection{Coping capabilities}

As it is impossible to anticipate all relevant future events (Lengnick-Hall and Beck 2005), organizations must also be able to cope effectively with critical events after they have manifested themselves. Coping generally refers to the development and implementation of solutions for a specific problem (Duchek 2014, 2019). Diversity can facilitate the coping stage because of its influence on (1) sensemaking and (2) problem-solving in complex settings.

(1) Sensemaking Coping with critical situations is always a combination of sensemaking and acting (Weick et al. 2005). Only if people are able to understand a crisis situation can they act on it (e.g., Weick 1993; Weick et al. 2005). Sensemaking capabilities help organizations to interpret and understand adverse events and thus build the foundation for problem-solving.

Diversity plays an important role in collective sensemaking, regardless of the kind of diversity. Weick (2001) argued that the fact of divergence is more important than the substance of divergence. It is important that people look at things differently when they size up a problem. Only then can a unit see more than one member alone could see. Stephens et al. (2013) described diversity as helpful for resilient coping by constructing a greater variety of interpretations for adverse situations (see also Eisenhardt et al. 1998; George and King 2007). Similarly, Saurin et al. (2013) argued that great diversity is important for resilience, as it offers a deeper understanding of the organizational context, thus providing a more precise basis for decision making and for actions to take. Diversity studies have also supported the notion that diverse work units can assist sensemaking processes. For example, Neill et al. (2007) showed that functional team diversity can promote organizational sensemaking capabilities. Their study also points to the role of an open-minded organizational culture as an antecedent of sensemaking capabilities.

Our experts also state that purposefully blended work units foster the ability to understand and interpret upcoming developments. They maintain that diverse work units take different views into account, avoid simplified unilateral interpretations of highly complex business environments, and can, thereby, better evaluate the risk potential of different developments:

The more perspectives that are represented on a team, the more discussion arises about how several risks should be evaluated (Expert $\mathrm{C}$ ).

Such [diverse] teams contain different perspectives ... that is why there might be less group think within the teams, and upcoming events might be assessed more critically and differentiated (Expert I).

(2) Problem-solving After the interpretation and understanding of a present crisis, organizations need to develop concrete solutions to cope with it in a resilient manner. This includes the appropriate use of gathered information, the transformation of information into adequate solutions and, finally, the consensual selection and implementation of the best options in a timely manner (e.g., Delbecq and van de Ven 1971; Svenson 1979). As crises are complex and cannot usually be solved with existing approaches, developing solutions demands broad knowledge, the 
interaction of different people (i.e., communication, knowledge sharing, coordination, conflict resolution), and creativity in making use of limited resources (referred to by Weick (1993) as "improvisation and bricolage").

In the resilience literature, the development of adequate and novel solutions in the face of a crisis is the most frequently mentioned use of diversity for resilient coping (see, e.g., Sutcliffe and Vogus 2003; Gomes et al. 2014; Pregenzer 2014). Sutcliffe and Vogus (2003) argued that experiential diversity can enlarge the ability of a work unit to grasp a situation and cope with the details, as their broad experiences can help their members to better recombine their knowledge, skills, and abilities into novel solutions (Bunderson and Sutcliffe 2002; Weick et al. 1999). In addition, Pregenzer (2014) asserted that the diversity of skills, personalities, and perspectives could enhance creativity and innovation, resulting in improvements in decision making and problem solving (see also Ely and Roberts 2008). This is supported by the empirical findings of Gomes et al. (2014). In their case study of teams at a simulated nuclear power plant, they found diversity to be a potential source of resilient coping. They argued that, due to the variety of potential responses in unknown and critical situations (in their case a nuclear disaster simulation), utilizing individuals with a wide range of different backgrounds seems to be useful for making better decisions (see also Hong and Page 2004).

Diversity research has also linked diversity with the concept of problem solving. In particular, diversity researchers from the information/decision-making perspective agree that functional or background diversity provides a range of knowledge, skills, and contacts that may enhance problem solving (e.g., Bantel and Jackson 1989; Ancona and Caldwell 1992; Williams and O'Reilly 1998; Pelled et al. 1999). This broader knowledge base may be particularly valuable for coping with unusual and complex problems; it causes work units to include different information and reconcile diverse perspectives, which helps them achieve more creative and innovative solutions (van Knippenberg and Schippers 2007). This implies that "at the core of the positive effects of diversity emphasized in the information/decisionmaking perspective lies elaboration of task-relevant information-the group-level exchange, processing, and integration of diverse information and perspectives" (van Knippenberg and Schippers 2007, p. 527). Empirical studies have confirmed the positive impact of diversity on problem-solving and thus positive team outcomes (Cox and Blake 1991; Watson et al. 1993; Pelled 1996).

However, researchers from the social-categorization perspective have argued to the contrary. They take the position that "differences between work group members may engender the classification of others as either ingroup/similar or outgroup/ dissimilar, categorizations that may disrupt group process" (van Knippenberg and Schippers 2007, p. 517), thereby having a negative impact on team outcomes (Horwitz and Horwitz 2007). From this angle, diversity is seen as a potential source of negative aspects such as disruptions, conflicts, or reduced team cooperation (van Knippenberg and Schippers 2007). This implies that diversity can also be dysfunctional and slow down the problem-solving process (for empirical evidence, see Jehn et al. 1999; Morrison and Milliken 2000). Especially in crisis situations, in which teams must react quickly, this would be problematic. Furthermore, conflicts and difficulties reconciling diverse perspectives might prevent diverse teams from 
coping effectively with crises. Therefore, diversity management is essential for ensuring positive diversity effects. Recent research has pointed to the important role of leadership (Kearney et al. 2009; Hoch 2014) or further supportive conditions such as team climate and culture, team size, and task characteristics (for reviews, see van Knippenberg et al. 2004; Guillaume et al. 2017). All these factors may promote or reduce the potential of diverse teams to solve problems effectively and in a timely manner.

One very significant moderating factor is task characteristics. Van Knippenberg et al. (2004) maintained that diversity may be more important for tasks with stronger information-processing and/or decision-making requirements, as its positive effects are generated by a more comprehensive group information processing. This is also supported by empirical evidence. Jehn et al. (1999) demonstrated that informational diversity is strongly positively related to group performance on less-routine tasks. Similarly, Bowers et al. (2000) found that diversity is positively related to group performance on more complex tasks but negatively related on simpler tasks. Furthermore, Weick and Sutcliffe (2015) noted the importance of bringing expertise to bear on complex problems. They argued that "HROs cultivate diversity, not just because it helps them notice more in complex environments, but also because it helps them do more with the complexities they spot" (Weick and Sutcliffe 2015, p. 14). Thus, the influence of diversity might be greater in complex critical situations.

Our experts strongly argue that heterogeneous experiences within work units can be useful for developing solutions in critical situations:

Having different experiences in the team concerning crisis management as well as different ideas and tools to handle a specific crisis is a strong advantage during the process of coping (Expert $\mathrm{J}$ ).

Everyone has different ideas. That is why there is much more creativity and innovation [in diverse teams]. In my opinion, this enables the company to overcome problems and challenges much faster (Expert G).

For this, however, you need many different thinking people to come together with their experiences quickly and creatively and propose the right solutions. And I believe this might make the reconciliation process more difficult, the more people who are involved in a decision. Anyway, the chance is much better explored (Expert D).

Conclusion Overall, we suggest that diversity plays an important role in the organizational coping process. In reaction to unexpected events, diversity may contribute to sensemaking capabilities and allows for a better understanding of acute crises. Furthermore, diversity can be useful in the problem-solving process, especially in more complex settings. In summary, we can formulate the following proposition:

Proposition 2 Diversity positively influences the development of coping capabilities by improving $(a)$ the sensemaking and $(b)$ the problem-solving capabilities of an organization. 


\subsubsection{Adaptation capabilities}

Adaptation goes beyond the restoration of organizational functionality and focuses particularly on the development of new capabilities (e.g., Sutcliffe and Vogus 2003; Lengnick-Hall and Beck 2005; Vogus and Sutcliffe 2007; Huber et al. 2009; Lengnick-Hall et al. 2011). It refers to adjustments following crises to produce a dynamic capability that is directed toward facilitating organizational change (Duchek 2014, 2019; Limnios et al. 2014) and long-term learning (Madni and Jackson 2009). Organizations can learn from prior crises and thereby be better prepared for future ones. This helps organizations to broaden their knowledge base, which, in turn, is a main antecedent of the anticipation dimension. For successful adaptation, both cognition and behavior are necessary. On the one hand, organizations must be able to reflect on the critical situation and incorporate the gained insight into the existing knowledge base. On the other hand, they must be able to act on this knowledge and produce change (Edmondson 2002). Diversity may enhance the organization's ability to (1) reflect on and (2) learn from critical events.

(1) Reflection Previous research has indicated that diverse work units can be better in terms of reflecting on a survived crisis. For example, Haunschild and Sullivan (2002) argued that heterogeneous experiences help organizations to focus attention on potential causes and perform a detailed analysis, force a situational analysis, and produce constructive conflict in groups. Moreover, a growing body of work links diversity with team reflection or reflexivity. Van Knippenberg and Schippers (2007) argued that divergent viewpoints can stimulate team reflexivity. Several empirical studies have confirmed this positive relationship between team diversity and reflexivity (see, e.g., West 2002; Haward et al. 2003; Schippers et al. 2003; Fay et al. 2006). For example, Schippers et al. (2003) studied the relationship between team diversity and reflexivity more closely and found that this relationship is moderated by outcome interdependence. Diverse groups that were highly outcome interdependent were more reflective than groups that were less outcome interdependent. This can be explained by the group's common goal that requires reflection.

(2) Learning After reflecting on a past crisis, learning from this experience is important for the proactive development of resilience. Learning at the group level can be understood as an interaction process characterized by "asking questions, seeking feedback, experimenting, reflecting on results, and discussing errors or unexpected outcomes of actions" (Edmondson 1999, p. 353). Research on the management of organizational failure already points to diversity as useful for learning. Reason (1997) argued that, in crisis situations, organizations are often aware of active (human) failures but fail to look at the underlying reasons and conditions. Diversity in perspectives forces organizations to avoid simple interpretations through constructive conflict and deeper discussions about actions to take (Haunschild and Sullivan 2002). Thus, diverse knowledge bases may reduce the tendency to focus on the surface and promote organizational function logic instead of individual blame (Catino 2008) when explaining failures (Gressgård and Hansen 2015). 
Diversity research has also confirmed the important role of diversity in team learning (see, e.g., Fiol 1994; Edmondson 1999; Gibson and Vermeulen 2003; van der Vegt and Bunderson 2005; Sun et al. 2017). Recent research has investigated the effects of team composition on team learning and performance and points to (demographic or functional) diversity as positive for team learning (Gibson and Vermeulen 2003; Lau and Murnighan 2005; van der Vegt and Bunderson 2005). For instance, Edmondson and Roloff (2009) argued that expertise diversity within crossfunctional teams may positively contribute to learning behaviors because it allows for combining different perspectives and qualified information. They also pointed out that positive conflict may protect teams from groupthink. Furthermore, several studies examined variables that mediate the relationship between diversity and team learning. For instance, van der Vegt and Bunderson (2005) argued that collective team identification moderates the effects of diversity on learning behavior and performance. Edmondson (1999) investigated four types of teams (functional, selfmanaged, cross-functional-development, and project teams) and was able to show that team design and leadership can enhance psychological safety and impact learning behavior.

Many of our experts explain that diverse teams encourage a more differentiated and more comprehensive reflection of already experienced crises and, consequently, an improved development of lessons learned and learning from those experiences in general. They argue that heterogeneous teams, compared to homogeneous ones, benefit in the interpretation process of experienced crises from their broader knowledge base, which aids in learning as much as possible from a crisis:

Various perspectives and experiences might also add value to the learning process of an organization, which includes the development of lessons learned as well as the further development of the firm itself. When reflecting on the crisis in the end, the interpretations of it might be different. ... And then, when transferring lessons learned to the future,... I am truly convinced that the various perspectives and manifold interpretations can help to make the company more crisis-proof in the future (Expert A).

Various characters and different types [of people] perceive crises in different ways. And by collecting and compiling all these perspectives, the most realistic and honest picture [of the last crisis situation] is generated (Expert $G$ ).

In my opinion, a mono-structured firm is not as able to learn as a multistructured one because it has less intrinsic motivation for learning (Expert C).

Conclusion The preceding discussion shows that diversity may contribute to adaptation capabilities. Diversity helps organizations broaden their knowledge base and, thus, be more successful in the next crisis situation. In particular, diversity can contribute to a better reflection of experienced crises and to more effective learning from those crises.

Proposition 3 Diversity positively influences the development of adaptation capabilities by improving $(a)$ the reflection of and $(b)$ the learning from alreadyexperienced crises. 


\subsection{Resilience-enhancing diversity management (REDM)}

The complexity associated with diversity places organizations in a paradoxical situation in which diversity is both a great opportunity and a challenge. Previous research has argued that diversity is valuable for becoming resilient (Sutcliffe and Vogus 2003); however, heterogeneity can also be dysfunctional and, thus, has limited value unless it is well managed (Eisenhardt et al. 1998). In our study, many interviewees highlighted that fact:

You should not forget: At the beginning, diversity means more complexity, so finding a solution takes a bit longer, but the solution is then more sustainable (Expert $\mathrm{H}$ ).

Baral (2013) also clarified that diversity adds further complexity to organizations. Beyond a certain threshold, diversity can create different problems. The high costs of trust-building, coordination, and conflict management in diverse teams can neutralize the positive effects of diversity and even negatively affect critical organizational functions (Garcia-Prieto et al. 2003; Triandis 2003; Ely 2004; Choi and Rainey 2010). Milliken and Martins (1996) used the metaphor of a doubleedged sword to argue that diversity may increase creativity but can lead to dissatisfaction and a lack of identification with the team. In such cases, diversity can also lead to diminishing resilience (Baral 2013).

To avoid the negative effects of diversity and use its full potential for resilience, organizations need purposefully designed diversity management. Our study indicates that, to develop resilience, it is not enough to have diverse work units; they must also be well managed. One interviewee states:

But there are also many situations where you are well advised to have a diverse team. But this must be moderated. This needs practice, expertise, you must be convinced of it. So, this needs certain spadework (Expert B).

This is also confirmed by Baral (2013), whose data indicated a curvilinear relationship between diversity and resilience. He asserted that appropriate diversity management practices and policies can minimize the negative impacts of a high level of diversity (Varughese and Ostrom 2001; Chi et al. 2009; Choi and Rainey 2010). Diversity is a recognizable source of resilience and a competitive advantage if organizations are able to handle it sensitively. This challenge can be addressed by resilience-enhancing diversity management (REDM), which can be understood as the systematic and planned commitment to diversity to achieve high levels of resilience. REDM aims at fostering positive diversity effects and exploiting potential chances for resilience while minimizing negative effects resulting from heterogeneity.

Based on these assumptions, we identified specific components of REDM in the second step of our analysis. The most important elements are (1) a resilienceenhancing diversity culture, (2) resilience-enhancing unit conditions, and (3) resilience-enhancing leadership. In general, these findings correspond with recent diversity research on moderating variables (on the relationship between workplace diversity and diversity outcomes) (e.g., Guillaume et al. 2017). However, we focus 
specifically on elements that are of particular importance for the development of organizational resilience.

\subsubsection{Resilience-enhancing diversity culture}

First, we consider the role of organizational culture as a moderating variable on the effects of diversity on resilience. Previous literature has indicated that the positive effects of diversity depend largely on organizational or contextual factors (Jackson et al. 2003; Mannix and Neale 2005; van Knippenberg and Schippers 2007). In particular, a culture of diversity that is characterized by the appreciation of variety and an openness toward differences is likely to accelerate positive outcomes in diverse work units (see, e.g., Cox 1994; Ely and Thomas 2001; Hofhuis et al. 2012; Guillaume et al. 2017). Thus, we consider two aspects of organizational culture as central components of REDM, namely valuing diversity and openness and communication.

(1) The aspect of valuing diversity is based on employees' perceptions of the extent to which they feel valued and the degree to which diversity is viewed as a competitive advantage for the organization (Cox and Blake 1991; Gardenswartz and Rowe 1998; Thompson 2016). Previous research has highlighted the importance of organizational culture for diversity management by linking it to the stages of cultural change from a monocultural (diversity-rejecting) to a multicultural (diversity-accepting) organization (e.g., Cox 1991, 2001). Only in a multicultural organization where diversity is valued in the sense that it is seen as an opportunity for learning and integration (Ely and Thomas 2001) can diversity's positive effects on work-unit outcomes (Chatman et al. 1998; Chattopadhyay et al. 2004; Homan et al. 2007) and members of all groups reach their full potential (Cox 2001). In particular, previous research has indicated that a belief in the value of diversity increases employees' identification with a work unit (van Knippenberg and Schippers 2007; van Dick et al. 2008) and may reduce potential conflicts that can result from diversity (Chatman et al. 1998; Chatman and Spataro 2005). Thus, a culture that values diversity can support favorable positive effects and prevent any negative effects of diversity. This also seems to be the case from a resilience perspective. In their case study, Groggins and Ryan (2013) showed that a climate that emphasizes diversity as a central, enduring, and distinctive organizational attribute is associated with openness not only toward others but also toward error and change in organizations, thus allowing them to develop the competencies required to deal effectively with challenges and to support continuous improvement. Similarly, Lengnick-Hall et al. (2011) proposed that organizations should attach great importance to individual differences and pluralism as an HR principle for facilitating the capacity of resilience. Bardoel et al. (2014, p. 287) pointed out that "if diversity management is used in conjunction with inclusive practices (Childs 2005), employees may develop strong bonds with other employees, supervisors and managers, and those bonds may serve as a resource, thereby facilitating resiliency." Our experts also confirm that employees must feel valued in their diversity to use their full resilience potential: 
When employees can be part of the firm in all their plurality, when they are strengthened in their individuality, then strong teams can emerge, which, in turn, are more able to react to imponderables..... When energy is used for avoidance rather than for openly dealing with oneself, individuals are massively losing productivity, creativity, and resilience, which, in turn, is bad for the firm. Therefore, successful dealings with personal variety and strengthening organizational resilience are clearly connected (Expert I).

(2) The second aspect, openness and communication, is at least as important. The entire organization's successful commitment to diversity can be achieved only by applying a proactive synergistic use of diversity at different levels and in different functions (e.g., Nishii 2013; Dwertmann et al. 2016). This includes a high level of openness within the organization and the promotion of information elaboration within work units (e.g., van Knippenberg et al. 2013). For management, this means it is not enough to value diversity and prevent its negative effects; it must also inform employees about these attitudes and, most importantly, convince them to adopt and include these attitudes in practice (e.g., Pless and Maak 2004; Groggins and Ryan 2013). In this context, research highlights the need for open and frank communication (Pless and Maak 2004). Hofhuis et al. (2016) found evidence that trustful and open communication within diverse work units is generally important, as it mediates the relationship between work-unit diversity and several positive outcomes (e.g., work-group identification, knowledge sharing), as pointed out by our interviewees in a similar manner:

I think that communication is very much needed to create a real cooperation, an open and honest opportunity to communicate in the firm, so that no employee is afraid to ask critical questions, to identify mistakes and, conversely, to be allowed to make mistakes (Expert G).

Furthermore, openness and communication are also seen as important factors in shaping the resilience of an organization, as they help to achieve a shared situational awareness as well as better interpretation and assessment of critical situations, thereby leading to more consistent and reliable decision-making processes in such situations (van der Vorm et al. 2011; Gomes et al. 2014). Accordingly, LengnickHall et al. (2011) described the creation of a climate characterized by open communication and collaboration as another important practice for facilitating an organization's capacity for resilience.

Consequently, we assume that if the organization succeeds in sharing its positive attitudes toward diversity, beneficial effects for coping with critical situations and, thus, for resilience can arise (e.g., Sutcliffe and Vogus 2003; Lengnick-Hall et al. 2011). This open organizational culture can also help to identify and utilize specific competences for dealing with crisis situations (see, e.g., Burnard et al. 2018), as also mentioned by one of our interviewees:

If the firm is well informed about the diversity of its staff, it might use specific abilities of specific people for crisis management that it hadn't been aware of before (Expert K). 
To create and ensure a resilience-enhancing organizational culture, important measures can include managerial information provision (see, e.g., Lenox and King 2004) and diversity trainings (e.g., Roberson et al. 2001; Pendry et al. 2007; Bezrukova et al. 2012, 2016). For example, diversity awareness training can help to increase employees' openness toward diversity inside the organization and create an understanding of the need for and meaning of valuing diversity. Skill-building training may further promote specific behavioral skills such as handling conflict or overcoming communication barriers (Roberson et al. 2001; Bezrukova et al. 2012, 2016). Our interviewees suggest:

This can be the creation of awareness through a "social day." That can simply be to have a diversity department and the implementation of diversity in all products (Expert E).

That generally starts with the management-down from the top-and diversity management can be helpful through specific training, concrete examples, best practices of the firm, best practices of other firms, [and] showing advantages, but also to help managers and employees through specific training to deal effectively with this diversity (Expert A).

Based on these insights, we can formulate our fourth proposition:

Proposition 4 Resilience-enhancing diversity management can positively moderate the relationship between diversity and resilience by offering a culture of (a) valuing diversity and (b) general openness and communication within the organization.

\subsubsection{Resilience-enhancing unit conditions}

As successful cooperation within heterogeneous units depends on the behavior of the people involved, current research has raised the question of the role of an adequate unit design in lifting the potential for diversity in organizations (e.g., Harrison and Humphrey 2010; Guillaume et al. 2017) as well as in enhancing their resilience (e.g., Maynard and Kennedy 2016; Williams et al. 2017). Thus, we argue that adequate management of three unit conditions-time span, unit composition, and unit coordination - should be a central part of REDM.

(1) The first unit condition is the time span during which a diverse team works together. Even early studies pointed out that diverse teams initially tend to perform worse than more homogeneous teams, but that they become more effective over time so that their performance can match or even exceed that of homogeneous groups (e.g., Gruenfeld et al. 1996; Earley and Mosakowski 2000). Our experts confirm that diverse teams need experience working together in order to perform well (especially during unexpected situations):

There are situations where diverse teams are useless, especially if they have no experience working together (Expert B).

Research has shown that temporal and life-cycle factors are important moderators for positive diversity outcomes (e.g., Jackson et al. 2003; Horwitz 2005; Guillaume 
et al. 2017), as more time working together involves interaction and collaboration and, thereby, allows group members to get to know each other (see, e.g., Harrison et al. 1998; 2002; Gonzalez 2010). More specifically, van Knippenberg et al. (2004, p. 1018) maintained that time allows members of diverse units to develop "the knowledge, skills, and abilities required to elaborate divergent perspectives and to develop a shared sense of "who knows what'." Greater unit tenure is also associated with the development of better mutual understanding, unique interests, values, and a diversity-oriented team culture (Earley and Mosakowski 2000; Gonzalez 2010) and, consequently, minimized stereotype-based classifications (Harrison et al. 1998, 2002).

Sufficient time for team development has also been linked to resilience in organizations. Edson (2012) asserted that team resilience is closely connected to a group's life-cycle stage because if team members do not know each other, it is not possible for them to respond effectively to unexpected events. New teams have not yet developed a virtual role system (Weick 1993) or relational reserves (Gittell et al. 2006), which are necessary to cope effectively with the unexpected. Researchers have also highlighted the role of social resources and processes (e.g., social support climate, social capital, or collective efficacy) in building resilience (e.g., Carmeli et al. 2013; Meneghel et al. 2016). Their development also needs a certain amount of time-and even more if teams are diverse and have to overcome difficulties in the first place.

Therefore, in order to achieve greater resilience, organizations should not change the composition of their diverse units too often or too quickly. Additionally, in complex and unstable environments, they should consider assigning responsibilities to more experienced teams.

(2) The second important unit condition is unit composition. From the categorization-elaboration model (van Knippenberg et al. 2004) and similar concepts, we know that diversity usually creates a better foundation for the elaboration of task-relevant information and perspectives, but that it can also hinder the use of this knowledge because of interpersonal disagreements. As managers have control over several compositional variables (e.g., demographics, types of diversity, unit size), it is argued that they should create diverse units purposefully in a way that allows for effective performance (Guillaume et al. 2017), which is also highlighted by our experts:

... teams are not randomly mixed ..., but consciously built. And then [the challenge is] to get the right people in the right mix-old/young, man/woman, different nations with all sorts of variety (Expert C).

Diversity seems to be generally supportive for an organization's resilience, as it provides a broader collective knowledge base-meaning different viewpoints, competencies, and repertoires (Weick 1979; Sutcliffe and Vogus 2003). However, research also indicates that specific forms of diversity are particularly helpful for encouraging the use of this knowledge, while other forms can potentially hinder this process. It is argued that experiential diversity (a mix of generalists and experts) helps teams to identify critical developments and act on that (Westrum 1991) as well as to recombine the existing knowledge into novel solutions (Weick et al. 1999; 
Bunderson and Sutcliffe 2002). In contrast, strong deep-level differences (regarding basic values, attitudes, and beliefs) and strong differences in team members' dispositional affect are associated with negative impacts on a team's crisis effectiveness by causing an increased perception of differences and more negative emotions, thus reducing social integration and, indirectly, team performance (Harrison et al. 1998; Bell 2007; Harvey 2013; Kaplan et al. 2013). Consequently, organizations have to be aware of these connections and should use this knowledge to compose diverse units with a view to resilience promotion.

(3) The last unit condition is adequate unit coordination. As mentioned, it is not only the duration that units work together that makes them successful but also behavioral mechanisms. For example, Harrison et al. $(1998,2002)$ argued that collaboration (understood as time spent in interactions) allows unit members to exchange personal and task-related information and thus supports performance by enhancing social integration. Similarly, Horwitz (2005) stated that the frequency and duration of member interactions moderate the relationship between a unit's diversity and its performance, as interaction allows unit members to integrate and develop a team identity (Gersick 1988; McGrath 1991). These complex, underlying processes of well-functioning diverse units are also highlighted by our interviewees:

... there isn't one feature ..., but a combination that makes teams of different people into high-performing teams that can effectively respond to crises because they live variety-knowledge sharing, trust, support, celebrating successes as teams, hope and honest communication, integrity, constructive feedback, et cetera (Expert I).

By taking a deeper look at such mechanisms, recent literature has illuminated the role of unit coordination. Zoogah et al. (2011, p. 254) described coordination as "a behavioral mechanism that facilitates transformation of team inputs to outputs (Kozlowski and Bell 2003) and can facilitate team performance." They point to the special importance of coordination for diverse work units, as those units must align their behaviors, goals, and activities in order to manage their interdependencies. By examining their assumptions within a sample of strategic alliance teams, they found robust support for the moderating role of coordination between gender diversity and team effectiveness and partial support for the moderating role of coordination between nationality diversity/functional diversity and team effectiveness. In addition, conceptual research has underscored the importance of relational coordination capabilities, as they are likely to promote social integration and well-being in diverse units (van Knippenberg et al. 2013; Guillaume et al. 2017).

In a similar vein, resilience-related research has emphasized the meaning of coordination (e.g., van der Vorm et al. 2011; Maynard and Kennedy 2016). Salanova et al. (2012) found evidence that coordination is an important interpersonal resource for a healthy and resilient organization (HERO) and a source of teamwork. In a more focused follow-up study, Meneghel et al. (2016) demonstrated that coordination as an important team resource positively contributes to team resilience. Faraj and Xiao (2006) argued that specific expertise coordination practices (e.g., knowledge sharing) are necessary to manage distributed knowledge 
and ensure the timely application of the needed expertise. Gittell (2002) showed that the performance effects of coordination mechanisms (e.g., team meetings) are mediated by relational coordination (a relationship-intensive form of coordination). Relationships characterized by shared goals, shared knowledge, and mutual respect lead to high levels of coordination and thus positive performance effects (Gittell 2001, 2002).

To ensure resilience-enhancing unit conditions, organizations have to be aware of the micro-mechanisms existing in diverse units and can utilize a broad set of supportive practices and tools. Validated instruments exist to assess the professional expertise (e.g., van der Heijden and Verhelst 2002), work-related competencies (e.g., Naquin and Wilson 2002), and central diversity aspects of organizational members (for deep-level diversity, see, e.g., Goldberg 1992 and Phillips 2003; for dispositional affect, see, e.g., Watson and Tellegen 1985; Watson et al. 1988). Competence-management systems could be beneficial (see, e.g., Hustad and Munkvold 2005; Draganidis and Mentzas 2006) for saving this knowledge and using it for compositional reasons. Moreover, to foster collaboration processes, organizations can use specific team-building activities (e.g., Ammeter and Dukerich 2002; Salas et al. 1999), team training (e.g., Leedom and Simon 1995; Bezrukova et al. 2012), and team rewards (Harrison et al. 2002).

In summary, our next proposition is:

Proposition 5 Resilience-enhancing diversity management can positively moderate the relationship between diversity and resilience by providing several unit conditions such as (a) sufficient time for effective teamwork, (b) suitable unit composition, and (c) adequate unit coordination.

\subsubsection{Resilience-enhancing leadership}

Current research agrees that leadership is critical for the performance of diverse work units (e.g., DiTomaso and Hooijberg 1996; Eagly and Chin 2010; Greer et al. 2012; Homan and Greer 2013). This leads to the assumption that leadership is also important for raising the resilience-enhancing potential of diverse work units and thus is a central element of REDM. While leading heterogeneous units is already a significant challenge, leading diverse units and realizing their resilience-enhancing potential is even more difficult. Leaders must foster the positive effects of diversity (see, e.g., Williams and O'Reilly 1998; van Knippenberg and Schippers 2007) and simultaneously prevent negative diversity effects (see, e.g., Horwitz and Horwitz 2007; van Knippenberg and Schippers 2007). To fulfill this task, leaders must have certain leadership qualities and appropriate leadership styles.

(1) The first aspect of adequate leadership involves certain qualities of the leader. Geert Hofstede pointed out that leading in diverse environments is like playing several musical instruments; it calls for different attitudes, skills, and knowledge (Connerley and Pedersen 2005), which is also highlighted by our experts:

... Because there is more discussion and more... friction. This is one of the challenges.... To provide the teams with a prejudice-free environment, that these teams can unfold (Expert C). 
Leaders must $\ldots$ be open to different personalities and backgrounds, and create a fruitful team atmosphere. Furthermore, they must handle more discussions and conflicts. To cope effectively with these challenges, leaders must possess various traits, abilities, and experiences. This needs practice, expertise, and you must be convinced of it (Expert B).

Leaders need to develop awareness, which means being open to and understanding other perspectives (Connerley and Pedersen 2005). Stephens et al. (2013) stated that diversity can only be helpful for coping with and adapting to adverse situations when leaders understand their own and others' perspectives (Eisenhardt et al. 1998) and are able to produce a variety of ways of interpreting adverse situations (George and King 2007). Furthermore, leaders need to possess specific skills and abilities, e.g., they must be able to learn and adapt, manage relationships, and cope with ambiguity (e.g., Maznevski and DiStefano 2000). They should also be highly resilient, as there is a positive relationship between a leader's resilience and employee work performance (Gooty et al. 2009; Walumbwa et al. 2010; Avey et al. 2011). Finally, leaders should be experienced in working with different people and different situations and thus have a broad knowledge base. Research has shown that, especially under stressful conditions, leaders with high levels of leadership experience demonstrate more effective performance (e.g., Fiedler 1994). Additionally, leadership experience can help leaders strengthen positive attitudes toward diversity and develop relevant leadership skills (Caligiuri and Tarique 2012).

(2) Beyond that, different leadership styles have been discussed as being appropriate in diverse work units (e.g., Somech 2006; Klein et al. 2011; Greer et al. 2012). The most studied are transformational leadership (Bass and Riggio 2006) and leader-member-exchange (Graen and Uhl-Bien 1995). In the resilience context, transformational leadership in particular has been mentioned as a resilienceenhancing leadership style (Harland et al. 2005; Morgan et al. 2015; Sommer et al. 2016). It is associated with greater levels of positive affect and lower levels of negative affect, thereby leading to greater resilience among team members (Sommer et al. 2016). In general, it can be said that leadership styles characterized by healing relationships, increasing trust, and solving conflicts are best suited to access the resilience-enhancing potential of diverse work units, as such styles may limit subgroup formation and foster exchange processes (e.g., Homan and Greer 2013). It is also important for leaders to be able to adapt their leadership style to accommodate different people and situations (see, e.g., Kuchinke 1999; Liu et al. 2003; Yu and Miller 2005). This is confirmed by one of our interviewees:

... if we have a leader who leads five different generations, to what extent is he able to respond to individual needs? Let me give another example: An employee who is new and very young, perhaps just graduated university ... needs another leadership style than someone who has been in the firm for thirty years. And that's, I think, something our superiors have a great influence on, our team leaders. And it is important to train them or simply provide support in order to respond to different needs (Expert $\mathrm{H}$ ). 
To ensure adequate, i.e., resilience-enhancing, leadership of diverse work units, important measures include purposeful leader selection, e.g., based on their leadership experience; specific leadership training, e.g., resilience training (Robertson et al. 2015); and general support for dealing with this difficult task, e.g., through opportunities for exchange with colleagues (Foerster and Duchek 2017).

Our last proposition is:

Proposition 6 Resilience-enhancing diversity management can positively moderate the relationship between diversity and resilience by fostering (a) certain leadership qualities and (b) adequate leadership styles.

\section{Implications and Future Prospects}

There is a large body of research on both organizational resilience and diversity in organizations. Although a few studies have already pointed to the potential link between diversity and resilience (see, e.g., Sutcliffe and Vogus 2003; Hong and Page 2004; Baral 2013), no research to date has attempted to link these two concepts at a deeper level. To the best of our knowledge, our paper is the first to offer a systematic connection of the elements of organizational resilience and the outcomes of diversity. In detail, we develop a theoretical framework that builds on a processbased approach of organizational resilience (Duchek 2014, 2019) and indicates the potential effects of diversity on underlying resilience capabilities. It can be shown that there are several potential effects of diversity (basically, work group diversity) on the three process stages of resilience (anticipation, coping, and adaptation). Based on our research, different theoretical and methodological implications for future research as well as practical implications for the resilience-enhancing management of diversity can be deduced; these are presented in the following sections.

\subsection{Theoretical implications}

Understanding organizational resilience as a process that depends on underlying process capabilities and routines (Duchek 2014, 2019) has proven to be a fruitful approach for investigating the effects of diversity on organizational resilience. In contrast to previous approaches that often treat organizational resilience as an outcome and identify resilience sources without explaining the underlying mechanisms of these connections (e.g., Horne and Orr 1998; Mallak 1998), the process-based approach offers a clear analytical framework that can serve as a basis for theoretical as well as empirical investigations on the effects of further important antecedents of organizational resilience (capabilities).

Furthermore, our study demonstrates that we can learn much from other research streams and, thereby, enhance our understanding of organizational resilience. In particular, our paper shows that we can build on diversity research to enhance our understanding of the resilience process and underlying process capabilities. The connection of diversity and organizational resilience has proved to be an interesting 
subject of investigation and one that requires further analysis. There is much research on the effects of diversity on both team- and organizational-level outcomes and, more recently, on moderating effects that have to be considered. While our work has attempted to link these two research streams on a more general level, further research might consider specific aspects in greater detail. For example, we occasionally suggest that there are specific effects of different diversity dimensions (e.g., demographic versus experiential diversity) but do not offer deeper insights on this point. As Milliken and Martins (1996) argued that different diversity types have different effects on organizational and team outcomes, and further research could investigate individual connections in a more focused approach.

Moreover, we use a broad understanding of diversity in work units and refer to different teams at different levels (e.g., top management teams or project teams). Thus, further research might focus on the role of diversity in the resilience of specific teams or organizations. For example, research has shown that project and entrepreneurial teams (e.g., Blatt 2009; Edson 2012; Amaral et al. 2015) as well as small- and medium-sized companies (e.g., Bhamra et al. 2011; Demmer et al. 2011) require high levels of resilience because of their limited resources and the uncertain and volatile environments in which they operate. It can be assumed that such units could particularly benefit from diversity, as it is a resilience resource that is relatively easy and inexpensive to acquire.

Additionally, along with other current research, we point to moderating factors that must be considered in order to realize the positive effects of diversity (e.g., van Knippenberg and Mell 2016; Guillaume et al. 2017). In particular, our study suggests the use of resilience-enhancing diversity management (REDM). The developed framework points to the main components of REDM and provides first insights into its implementation. However, the concrete design, implementation, and application of REDM require further examination and specification. Although we consider diversity to be important for resilience, it can be presumed that resilience may also be an important moderator for the relationship between diversity and performance. Therefore, further research could examine the reverse connection as well as interrelationships.

\subsection{Methodological implications}

To investigate the relationship between diversity and resilience, further research could extend and enhance our framework empirically. On the one hand, our paper illustrates the effects that diversity can have on resilience. Further studies might investigate in greater detail how these effects can be achieved. Because qualitative studies are not aimed at statistical generalizations (Mayring 2007), our results can be used as a starting point for quantitative analyses in order to validate and extend our findings. For this purpose, future studies could build on our formulated propositions.

On the other hand, further research could focus on the influence of diversity on the resilience of teams or organizations in greater detail. For this purpose, qualitative research methods seem to be suitable. For example, ethnographic studies (Rosen 1991; Ybema et al. 2009) can provide deeper insights into complex practices 
and processes that shape these connections. Beyond that, future research could take a longitudinal perspective to provide more information about the implementation, development, and changes of diversity and resilience-enhancing diversity management (for longitudinal studies on other diversity management approaches, see Carrell et al. 2006; Sippola and Smale 2007).

\subsection{Practical implications}

Our findings have a number of implications for managerial practice. We propose that there is a need for diversity in organizations, as diversity can help enhance organizational resilience. Thus, organizations should not attempt to avoid heterogeneity. Instead, they should enhance their knowledge base by including different people, perspectives, and backgrounds. This can be realized through open-minded and goal-oriented personnel recruitment and employment (Roberson et al. 2017). However, our paper also shows that it is not enough to build diverse work units (McKay and Avery 2005). Organizations also need appropriate diversity management that allows for effective use of the diversity potential at the work-unit level, as well as the transformation of work-unit outcomes into organizational-level outcomes (Jackson et al. 2003). For this purpose, (human resource) management must help to create a culture of diversity, train their (team) leaders at different organizational levels, and help employees cope with problems associated with diversity (Shen et al. 2009). Organizations could employ diversity managers who support necessary changes professionally (Dobbin and Kalev 2015).

\section{Conclusion}

The present paper analyzed the relationship between (work-unit) diversity and organizational resilience, which previously has scarcely been examined. For this purpose, we developed a conceptual framework building on a process-based understanding of organizational resilience (Duchek 2014, 2019) and connected the existing literature on elements of organizational resilience and outcomes of (workunit) diversity. The findings indicate the potential role of diversity in enhancing organizational resilience by contributing to the development of different capabilities underlying the three stages of the resilience process (anticipation, coping, and adaptation). Our study shows the relevance of diversity in all three stages. In particular, diversity can influence the development of anticipation capabilities by improving the observation and identification of critical changes and preparations for future events. By improving sensemaking and problem solving, diversity can promote coping capabilities. Finally, diversity can enhance organizational ability to reflect on and learn from critical situations and, therefore, promote adaptation capabilities. Furthermore, the study suggests resilience-enhancing diversity management (REDM) as a moderator for exploiting the full potential of diversity in enhancing resilience. Organizations have different opportunities to realize this potential. In particular, they can create a specific diversity culture (valuing and open), ensure particular unit conditions (time span, composition, coordination), and 
deploy (team) executives with appropriate leadership (qualities and styles). In summary, our paper contributes to the connection of two research streams and provides initial insights into the resilience-enhancing effect of diversity as well as the effective management of organizational resilience capabilities in diverse organizations. Moreover, it points to the necessity to intensify research in this area in order to shed light on the complex relationship between diversity and organizational resilience. Our findings can be used as a foundation for future empirical research.

Open Access This article is distributed under the terms of the Creative Commons Attribution 4.0 International License (http://creativecommons.org/licenses/by/4.0/), which permits unrestricted use, distribution, and reproduction in any medium, provided you give appropriate credit to the original author(s) and the source, provide a link to the Creative Commons license, and indicate if changes were made.

\section{References}

Açıkgöz, Atif, Ayşe Günsel, Cemil Kuzey, and Gökhan Seçgin. 2016. Functional diversity, absorptive capability and product success: the moderating role of project complexity in new product development teams. Creativity and Innovation Management 25 (1): 90-109.

Amaral, António, Aldora G. G. Fernandes, and João Varajão. 2015. Identifying useful actions to improve team resilience in information systems projects. Procedia Computer Science 64 (2015): 1182-1189.

Ammeter, Anthony P., and Janet M. Dukerich. 2002. Leadership, team building, and team member characteristics in high performance project teams. Engineering Management Journal 14 (4): 3-10.

Ancona, Deborah G., and David F. Caldwell. 1992. Demography and design: predictors of new product team performance. Organization Science 3 (3): 321-341.

Avey, James B., Bruce J. Avolio, and Fred Luthans. 2011. Experimentally analyzing the impact of leader positivity on follower positivity and performance. The Leadership Quarterly 22 (2): 282-294.

Bantel, Karen A., and Susan E. Jackson. 1989. Top management and innovations in banking: does the composition of the top team make a difference? Strategic Management Journal 10 (S1): 107-124.

Baral, Nabin. 2013. What makes grassroots conservation organizations resilient? An empirical analysis of diversity, organizational memory, and the number of leaders. Environmental Management 51 (3): 738-749.

Bardoel, E. Anne, Trisha M. Pettit, Helen De Cieri, and Lindsay McMillan. 2014. Employee resilience: an emerging challenge for HRM. Asia Pacific Journal of Human Resources 52 (3): 279-297.

Bass, Bernard M., and Ronald E. Riggio. 2006. Transformational leadership. Mahwah: Erlbaum.

Bell, Suzanne T. 2007. Deep-level composition variables as predictors of team performance: a metaanalysis. Journal of Applied Psychology 92 (3): 595-615.

Bezrukova, Katerina, Karen A. Jehn, and Chester S. Spell. 2012. Reviewing diversity training: where we have been and where we should go. Academy of Management Learning and Education 11 (2): 207-227.

Bezrukova, Katerina, Chester S. Spell, Jamie L. Perry, and Karen A. Jehn. 2016. A meta-analytical integration of over 40 years of research on diversity training evaluation. Psychological Bulletin 142 (11): 1227-1274.

Bhamra, Ran, Samir Dani, and Kevin Burnard. 2011. Resilience: the concept, a literature review and future directions. International Journal of Production Research 49 (18): 5375-5393.

Blatt, Ruth. 2009. Resilience in entrepreneurial teams: developing the capacity to pull through. Frontiers of Entrepreneurship Research 29 (11): 1-14.

Boin, Arjen, and Michel J. G. van Eeten. 2013. The resilient organization. Public Management Review 15 (3): 429-445.

Bowers, Clint A., James A. Pharmer, and Eduardo Salas. 2000. When member homogeneity is needed in work teams: a meta-analysis. Small Group Research 31 (3): 305-327. 
Bunderson, J. Stuart, and Kathleen M. Sutcliffe. 2002. Comparing alternative conceptualizations of functional diversity in management teams: process and performance effects. Academy of Management Journal 45 (5): 875-893.

Burnard, Kevin, and Ran Bhamra. 2011. Organisational resilience: development of a conceptual framework for organisational responses. International Journal of Production Research 49 (18): 5581-5599.

Burnard, Kevin, Ran Bhamra, and Christos Tsinopoulos. 2018. Building organisational resilience: four configurations. IEEE Transactions on Engineering Management 65 (3): 351-362.

Caligiuri, Paula, and Ibraiz Tarique. 2012. Dynamic cross-cultural competencies and global leadership effectiveness. Journal of World Business 47 (4): 612-622.

Carmeli, Abraham, Yair Friedman, and Asher Tishler. 2013. Cultivating a resilient top management team: the importance of relational connections and strategic decision comprehensiveness. Safety Science 51 (1): 148-159.

Carrell, Michael R., Everett E. Mann, and Tracey H. Sigler. 2006. Defining workforce diversity programs and practices in organizations: a longitudinal study. Labor Law Journal 57 (1): 5-12.

Catino, Maurizio. 2008. A review of literature: individual blame vs organizational function logics in accident analysis. Journal of Contingencies and Crisis Management 16 (1): 53-62.

Chatman, Jennifer A., and Sandra E. Spataro. 2005. Using self-categorization theory to understand relational demography-based variations in people's responsiveness to organizational culture. Academy of Management Journal 48 (2): 321-331.

Chatman, Jennifer A., Jeffrey T. Polzer, Sigal G. Barsade, and Margaret A. Neale. 1998. Being different yet feeling similar: the influence of demographic composition and organizational culture on work processes and outcomes. Administrative Science Quarterly 43 (4): 749-780.

Chattopadhyay, Prithviraj, Malgorzata Tluchowska, and Elizabeth George. 2004. Identifying the ingroup: a closer look at the influence of demographic dissimilarity on employee social identification. Academy of Management Review 29 (2): 180-202.

Chi, Nai-Wen, Yin-Mai Huang, and Shu-Chin Lin. 2009. A double-edged sword? Exploring the curvilinear relationship between organizational tenure diversity and team innovation: the moderating role of team-oriented HR practices. Group and Organization Management 34 (6): 698-726.

Cho, Theresa S. 2006. The effects of executive turnover on top management team's environmental scanning behavior after an environmental change. Journal of Business Research 59 (10-11): 1142-1150.

Choi, Sungjoo, and Hal G. Rainey. 2010. Managing diversity in US federal agencies: effects of diversity and diversity management on employee perceptions of organizational performance. Public Administration Review 70 (1): 109-121.

Cohen, Wesley M., and Daniel A. Levinthal. 1990. Absorptive capacity: a new perspective on learning and innovation. Administrative Science Quarterly 35 (1): 128-152.

Connerley, Mary L., and Paul B. Pedersen. 2005. Leadership in a diverse and multicultural environment: developing awareness, knowledge, and skills. Thousand Oaks: Sage Publications.

Coutu, Diane L. 2002. How resilience works. Harvard Business Review 80 (5): 46-56.

Cox, Taylor H. 1991. The multicultural organization. The Executive 5 (2): 34-47.

Cox, Taylor H. 1994. Cultural diversity in organizations: theory, research and practice. San Francisco: Berrett Koehler Publishers.

Cox, Taylor H. 2001. Creating the multicultural organization: a strategy for capturing the power of diversity. San Francisco: Jossey-Bass.

Cox, Taylor H., and Stacy Blake. 1991. Managing cultural diversity: implications for organizational competitiveness. The Executive 5 (3): 45-56.

Dayan, Mumin, Muammer Ozer, and Hanan Almazrouei. 2017. The role of functional and demographic diversity on new product creativity and the moderating impact of project uncertainty. Industrial Marketing Management 61 (2017): 144-154.

Delbecq, Andre L., and Andrew H. van de Ven. 1971. A group process model for problem identification and program planning. The Journal of Applied Behavioral Science 7 (4): 466-492.

Demmer, William A., Shawnee K. Vickery, and Roger Calantone. 2011. Engendering resilience in smalland medium-sized enterprises (SMEs): a case study of Demmer Corporation. International Journal of Production Research 49 (18): 5395-5413.

DiTomaso, Nancy, and Robert Hooijberg. 1996. Diversity and the demands of leadership. Leadership Quarterly 7 (2): 163-187. 
Dobbin, Frank, and Alexandra Kalev. 2015. Why firms need diversity managers and task forces. In How global migration changes the workforce diversity equation, ed. Massimo Pilati, Hina Sheikh, Francesca Sperotti, and Chris Tilly, 170-198. Newcastle: Cambridge Scholars Publishing.

Draganidis, Fotis, and Gregoris Mentzas. 2006. Competency based management: a review of systems and approaches. Information Management and Computer Security 14 (1): 51-64.

Duchek, Stephanie. 2014. Growth in the face of crisis: the role of organizational resilience capabilities. Academy of Management Meeting Proceedings 2014 (1): 861-866.

Duchek, Stephanie 2019. Organizational resilience: a capability-based conceptualization. Business Research. https://doi.org/10.1007/s40685-019-0085-7.

Dwertmann, David J., Lisa H. Nishii, and Daan van Knippenberg. 2016. Disentangling the fairness \& discrimination and synergy perspectives on diversity climate: moving the field forward. Journal of Management 42 (5): 1136-1168.

Eagly, Alice H., and Jean Lau Chin. 2010. Diversity and leadership in a changing world. American Psychologist 65 (3): 216-225.

Earley, Christopher P., and Elaine Mosakowski. 2000. Creating hybrid team cultures: an empirical test of transnational team functioning. Academy of Management Journal 43 (1): 26-49.

Edmondson, Amy, and Kathryn Roloff. 2009. Leveraging diversity through psychological safety. Rotman Magazine: 47-51.

Edmondson, Amy. 1999. Psychological safety and learning behavior in work teams. Administrative Science Quarterly 44 (2): 350-383.

Edmondson, Amy. 2002. The local and variegated nature of learning in organizations: a group-level perspective. Organization Science 13 (2): 128-146.

Edson, Mary C. 2012. A complex adaptive systems view of resilience in a project team. Systems Research and Behavioral Science 29 (5): 499-516.

Eisenhardt, Kathleen M., Jean L. Kahwajy, and Louis J. Bourgeois. 1998. Conflict and strategic choice: how top management teams disagree. In Navigating change: how CEOs, top teams, and boards steer transformation, ed. Donald C. Hambrick, David A. Nadler, and Michael L. Tushman, 141-169. Boston: Harvard Business School Press.

Ely, Robin J. 2004. A field study of group diversity, participation in diversity education programs, and performance. Journal of Organizational Behavior 25 (6): 755-780.

Ely, Robin J., and David A. Thomas. 2001. Cultural diversity at work: the effects of diversity perspectives on work group processes and outcomes. Administrative Science Quarterly 46 (2): 229-273.

Ely, Robin J., and Laura M. Roberts. 2008. Shifting frames in team-diversity research: from difference to relationships. In Diversity at work, ed. Arthur P. Brief, 175-202. Cambridge: Cambridge University Press.

Faraj, Samer, and Yan Xiao. 2006. Coordination in fast-response organizations. Management Science 52 (8): 1155-1169.

Fay, Doris, Carol Borrill, Ziv Amir, Robert Haward, and Michael A. West. 2006. Getting the most out of multidisciplinary teams: a multi-sample study of team innovation in health care. Journal of Occupational and Organizational Psychology 79 (4): 553-567.

Ferreira, Pedro N. P., John R. Wilson, Brandon Ryan, and Sarah Sharples. 2011. Measering resilience in the planning of rail engineering work. In Resilience engineering in practice: a guidebook, ed. Erik Hollnagel, Jean Pariès, David D. Woods, and John Wreathall, 145-156. Aldershot: Ashgate

Fiedler, Fred E. 1994. Leadership experience and leadership performance. Washington: University Seattle.

Filatotchev, Igor, and Steve Toms. 2003. Corporate governance, strategy and survival in a declining industry: a study of UK cotton textile companies. Journal of Management Studies 40 (4): 895-920.

Fiol, C. Marlene. 1994. Consensus, diversity, and learning in organizations. Organization Science 5 (3): 403-420.

Foerster, Charlotte, and Stephanie Duchek. 2017. What makes leaders resilient? An exploratory interview study. German Journal of Human Resource Management 31 (4): 281-306.

Garcia-Prieto, Patricia, Erwan Bellard, and Susan C. Schneider. 2003. Experiencing diversity, conflict, and emotions in teams. Applied Psychology: An International Review 52 (3): 413-440.

Gardenswartz, Lee, and Anita Rowe. 1998. Managing diversity: a complete desk reference and planning guide. New York: McGraw-Hill.

George, Jennifer M., and Eden King. 2007. Potential pitfalls of affect convergence in teams: functions and dysfunctions of group affective tone. In Research on managing groups and teams, vol. 10, ed. 
Elisabeth A. Mannix, Margaret A. Neale, and Cameron P. Anderson, 97-123., Affect and groups Oxford: JAI Press.

Gersick, Connie J. 1988. Time and transition in work teams: toward a new model of group development. Academy of Management Journal 31 (1): 9-41.

Gibson, Cristina, and Freek Vermeulen. 2003. A healthy divide: subgroups as a stimulus for team learning behavior. Administrative Science Quarterly 48 (2): 202-239.

Gittell, Jody H. 2001. Supervisory span, relational coordination and flight departure performance: a reassessment of post-bureaucracy theory. Organization Science 12 (4): 467-482.

Gittell, Jody H. 2002. Coordinating mechanisms in care provider groups: relational coordination as a mediator and input uncertainty as a moderator of performance effects. Management Science 48 (11): 1408-1426.

Gittell, Jody H., Kim Cameron, Sandy Lim, and Victor Rivas. 2006. Relationships, layoffs, and organizational resilience: airline industry responses to September 11. The Journal of Applied Behavioral Science 42 (3): 300-329.

Glick, William H., C. Chet Miller, and George P. Huber. 1993. The impact of upper-echelon diversity on organizational performance. In Organizational change and redesign: ideas and insights for improving performance, ed. George P. Huber and William H. Glick, 176-214. New York: Oxford University Press.

Goldberg, Lewis R. 1992. The development of markers for the big-five factor structure. Psychological Assessment 4 (1): 26-42.

Gomes, José O., Marcos R. Borges, Gilbert J. Huber, and Paul V. R. Carvalho. 2014. Analysis of the resilience of team performance during a nuclear emergency response exercise. Applied Ergonomics 45 (3): 780-788.

Gonzalez, Jorge A. 2010. Diversity change in organizations: a systemic, multilevel, and nonlinear process. The Journal of Applied Behavioral Science 46 (2): 197-219.

Gooty, Janaki, Mark Gavin, Paul D. Johnson, M. Lance Frazier, and Bradley D. B. Snow. 2009. In the eyes of the beholder: transformational leadership, positive psychological capital, and performance. Journal of Leadership and Organizational Studies 15 (4): 353-367.

Graen, George B., and Mary Uhl-Bien. 1995. Relationship-based approach to leadership: development of leader-member exchange (LMX) theory of leadership over 25 years: applying a multi-level multidomain perspective. The Leadership Quarterly 6 (2): 219-247.

Greer, Lindred L., Astrid C. Homan, Annebel H. De Hoogh, and Deanne N. Den Hartog. 2012. Tainted visions: the effect of visionary leader behaviors and leader categorization tendencies on the financial performance of ethnically diverse teams. Journal of Applied Psychology 97 (1): 203-213.

Gressgård, Leif J., and Kare Hansen. 2015. Knowledge exchange and learning from failures in distributed environments: the role of contractor relationship management and work characteristics. Reliability Engineering and System Safety 133 (2015): 167-175.

Groggins, Ashley, and Ann Marie Ryan. 2013. Embracing uniqueness: the underpinnings of a positive climate for diversity. Journal of Occupational and Organizational Psychology 86 (2): 264-282.

Grote, Gudela. 2009. Management of uncertainty: theory and application in the design of systems and organizations. London: Springer.

Gruenfeld, Deborah H., Elizabeth A. Mannix, Kathrine Y. Williams, and Margaret A. Neale. 1996. Group composition and decision making: how member familiarity and information distribution affect process and performance. Organizational Behavior and Human Decision Processes 67 (1): 1-15.

Guillaume, Yves R. F., Jeremy F. Dawson, Lilian Otaye-Ebede, Stephen A. Woods, and Michael A. West. 2017. Harnessing demographic in organizations: what moderates the effects of workplace diversity? Journal of Organizational Behavior 38 (2): 276-303.

Hall, David C., and Scott C. Ellis. 2010. Core and overlapping knowledge, integration, and process performance: an empirical study of the buyer-product engineer dyad. Production and Operations Management Society Annual Meeting. Vancouver, Canada, May 7-10.

Hamel, Gary, and Liisa Vaelikangas. 2003. The quest for resilience. Harvard Business Review 81 (9): 52-63.

Haon, Christophe, David Gotteland, and Marianela Fornerino. 2009. Familiarity and competence diversity in new product development teams: effects on new product performance. Marketing Letters 20 (1): 75-89.

Harland, Lynn, Wayne Harrison, James R. Jones, and Roni Reiter-Palmon. 2005. Leadership behaviors and subordinate resilience. Journal of Leadership and Organizational Studies 11 (2): 2-14. 
Harrison, David A., and Katherine J. Klein. 2007. What's the difference? Diversity constructs as separation, variety, or disparity in organizations. Academy of Management Review 32 (4): 1199-1228.

Harrison, David A., and Stephen E. Humphrey. 2010. Designing for diversity or diversity for design? Tasks, interdependence, and within-unit differences at work. Journal of Organizational Behavior 31 (2-3): 328-337.

Harrison, David A., Kenneth H. Price, and Myrtle P. Bell. 1998. Beyond relational demography: time and the effects of surface-and deep-level diversity on work group cohesion. Academy of Management Journal 41 (1): 96-107.

Harrison, David A., Kenneth H. Price, Joanne H. Gavin, and Anna T. Florey. 2002. Time, teams, and task performance: changing effects of surface-and deep-level diversity on group functioning. Academy of Management Journal 45 (5): 1029-1045.

Harvey, Sarah. 2013. A different perspective: the multiple effects of deep level diversity on group creativity. Journal of Experimental Social Psychology 49 (5): 822-832.

Haunschild, Pamela R., and Bilian N. Sullivan. 2002. Learning from complexity: effects of prior accidents and incidents on airlines' learning. Administrative Science Quarterly 47 (4): 609-643.

Haward, Robert, Ziv Amir, Carol S. Borrill, Jeremy F. Dawson, Judy W. Scully, Michael A. West, and Richard Sainsbury. 2003. Breast cancer teams: the impact of constitution, new cancer workload, and methods of operation on their effectiveness. British Journal of Cancer 89 (1): 15-22.

Hoch, Julia E. 2014. Shared leadership, diversity, and information sharing in teams. Journal of Managerial Psychology 29 (5): 541-564.

Hofhuis, Joep, Karen I. van Der Zee, and Sabine Otten. 2012. Social identity patterns in culturally diverse organizations: the role of diversity climate. Journal of Applied Social Psychology 42 (4): 964-989.

Hofhuis, Joep, Pernill G. A. van der Rijt, and Martijn Vlug. 2016. Diversity climate enhances work outcomes through trust and openness in workgroup communication. SpringerPlus 5 (1): 714-727.

Homan, Astrid C., and Lindred L. Greer. 2013. Considering diversity: the positive effects of considerate leadership in diverse teams. Group Processes and Intergroup Relations 16 (1): 105-125.

Homan, Astrid C., Daan van Knippenberg, Gerben A. van Kleef, and Carsten K.W. De Dreu. 2007. Bridging faultlines by valuing diversity: diversity beliefs, information elaboration, and performance in diverse work groups. Journal of Applied Psychology 92 (5): 1189-1199.

Hong, Lu, and Scott E. Page. 2004. Groups of diverse problem solvers can outperform groups of highability problem solvers. Proceedings of the National academy of Sciences of the United States of America 101 (46): 16385-16389.

Horne, John F. 1997. The coming age of organizational resilience. Business Forum 22 (2/3): 24-28.

Horne, John F., and John E. Orr. 1998. Assessing behaviors that create resilient organizations. Employee Relations Today 24 (4): 29-39.

Horwitz, Sujin K. 2005. The compositional impact of team diversity on performance: theoretical considerations. Human Resource Development Review 4 (2): 219-245.

Horwitz, Sujin K., and Irwin B. Horwitz. 2007. The effects of team diversity on team outcomes: a metaanalytic review of team demography. Journal of Management 33 (6): 987-1015.

Huber, Stephanie, Ivette van Wijgerden, Arjan de Witt, and Sidney W. Dekker. 2009. Learning from organizational incidents: resilience engineering for high-risk process environments. Process Safety Progress 28 (1): 90-95.

Hustad, Eli, and Bjørn Erik Munkvold. 2005. IT-supported competence management: a case study at Ericsson. Information Systems Management 22 (2): 78-88.

International Monetary Fund. 2011. IMF performance in the run-up to the financial and economic crisis: IMF surveillance in 2004-07. Washington: International Monetary Fund.

Jackson, Susan E., and Aparna Joshi. 2011. Work team diversity. In APA handbook of industrial and organizational psychology, ed. Sheldon Zedeck, 651-686. Washington: American Psychological Association.

Jackson, Susan E., Aparna Joshi, and Niclas L. Erhardt. 2003. Recent research on team and organizational diversity: SWOT analysis and implications. Journal of Management 29 (6): 801-830.

Jackson, Susan E., Karen E. May, and Kristina Whitney. 1995. Understanding the dynamics of diversity in decision making teams. In Team effectiveness and decision making in organizations, ed. Richard A. Guzzo and Eduardo Salas, 204-261. San Francisco: Jossey-Bass.

Jehn, Karen A., Gregory B. Northcraft, and Margaret A. Neale. 1999. Why differences make a difference: a field study of diversity, conflict and performance in workgroups. Administrative Science Quarterly 44 (4): 741-764. 
Kaplan, Seth, Kate LaPort, and Mary J. Waller. 2013. The role of positive affectivity in team effectiveness during crises. Journal of Organizational Behavior 34 (4): 473-491.

Kearney, Eric, Diether Gebert, and Sven C. Voelpel. 2009. When and how diversity benefits teams: the importance of team members' need for cognition. Academy of Management Journal 52 (3): 581-598.

Keller, Robert T. 2001. Cross-functional project groups in research and new product development: diversity, communications, job stress, and outcomes. Academy of Management Journal 44 (3): 547-555.

Kendra, James M., and Tricia Wachtendorf. 2003. Elements of resilience after the World Trade Center disaster. Reconstituting New York City's emergency operations centre. Disasters 27 (1): 37-53.

Klein, Katherine J., Andrew P. Knight, Jonathan C. Ziegert, Beng Chong Lim, and Jessica L. Saltz. 2011. When team members' values differ: the moderating role of team leadership. Organizational Behavior and Human Decision Processes 114 (1): 25-36.

Kozlowski, Steve W., and Bradford S. Bell. 2003. Work groups and teams in organizations. In Handbook of psychology: industrial and organizational psychology, vol. 12, ed. Walter C. Borman, Daniel R. Ilgen, and Richard J. Klimoski, 333-375. Hoboken: Wiley.

Kuchinke, K. Peter. 1999. Leadership and culture: work-related values and leadership styles among one company's US and German telecommunication employees. Human Resource Development Quarterly 10 (2): 135-154.

Lau, Dora C., and J. Murnighan. 2005. Interactions within groups and subgroups: the effects of demographic faultlines. Academy of Management Journal 48 (4): 645-659.

Leedom, Dennis K., and Robert Simon. 1995. Improving team coordination: a case for behavior-based training. Military Psychology 7 (2): 109-122.

Lengnick-Hall, Cynthia A., and Tammy E. Beck. 2005. Adaptive fit versus robust transformation: how organizations respond to environmental change. Journal of Management 31 (5): 738-757.

Lengnick-Hall, Cynthia A., Tammy E. Beck, and Mark L. Lengnick-Hall. 2011. Developing a capacity for organizational resilience through strategic human resource management. Human Resource Management Review 21 (3): 243-255.

Lenox, Michael, and Andrew King. 2004. Prospects for developing absorptive capacity through internal information provision. Strategic Management Journal 25 (4): 331-345.

Limnios, Elena A. M., Tim Mazzarol, Anas Ghadouani, and Steven G. M. Schilizzi. 2014. The resilience architecture framework: four organizational archetypes. European Management Journal 32 (1): 104-116.

Linnenluecke, Martina K. 2017. Resilience in business and management research: a review of influential publications and a research agenda. International Journal of Management Reviews 19 (1): 4-30.

Linnenluecke, Martina K., and Andrew Griffiths. 2012. Assessing organizational resilience to climate and weather extremes: complexities and methodological pathways. Climatic Change 113 (3-4): 933-947.

Liu, Wei, David P. Lepak, Riki Takeuchi, and Henry P. Sims Jr. 2003. Matching leadership styles with employment modes: strategic human resource management perspective. Human Resource Management Review 13 (1): 127-152.

Madni, Azad M., and Scott Jackson. 2009. Towards a conceptual framework for resilience engineering. IEEE Systems Journal 3 (2): 181-191.

Mallak, Larry A. 1998. Measuring resilience in health care provider organizations. Health Manpower Management 24 (4): 148-152.

Mannix, Elizabeth, and Margaret A. Neale. 2005. What differences make a difference? The promise and reality of diverse teams in organizations. Psychological Science in the Public Interest 6 (2): 31-55.

Maynard, M. Travis, and Deanne M. Kennedy. 2016. Team adaptation and resilience: what do we know and what can be applied to long-duration isolated, confined, and extreme contexts. Houston: National Aeronautics and Space Administration.

Mayring, Philipp. 2007. On generalization in qualitatively oriented research. Forum: Qualitative Social Research 8 (3): 1-9.

Maznevski, Martha L., and Joseph J. DiStefano. 2000. Global leaders are team players: developing global leaders through membership on global teams. Human Resource Management 39 (2-3): 195-208.

McCann, Joseph, and John W. Selsky. 2012. Mastering turbulence: the essential capabilities of agile and resilient individuals, teams, and organizations. San Francisco: Jossey-Bass.

McCann, Joseph, John W. Selsky, and James Lee. 2009. Building agility, resilience and performance in turbulent environments. People and Strategy 32 (3): 44-51. 
McGrath, Joseph E. 1991. Time, interaction, and performance (TIP): a Theory of Groups. Small Group Research 22 (2): 147-174.

McKay, Patrick F., and Derek R. Avery. 2005. Warning! Diversity recruitment could backfire. Journal of Management Inquiry 14 (4): 330-336.

Meneghel, Isabelle, Isabel M. Martínez, and Marisa Salanova. 2016. Job-related antecedents of team resilience and improved team performance. Personnel Review 45 (3): 505-522.

Milliken, Frances J., and Luis L. Martins. 1996. Searching for common threads: understanding the multiple effects of diversity in organizational groups. Academy of Management Review 21 (2): 402-433.

Milliken, Frances J., Caroline A. Bartel, and Terri R. Kurtzberg. 2003. Diversity and creativity in work groups: a dynamic perspective on the affective and cognitive processes that link diversity and performance. In Group creativity: innovation through collaboration, ed. Paul B. Paulus and Bernard A. Nijstad, 32-62. Oxford: Oxford University Press.

Momani, Bessma. 2007. IMF staff: missing link in fund reform proposals. The Review of International Organizations 2 (1): 39-57.

Morgan, Paul B., David Fletcher, and Mustafa Sarkar. 2015. Understanding team resilience in the world's best athletes: a case study of a rugby union World Cup winning team. Psychology of Sport and Exercise 16 (2015): 91-100.

Morrison, Elizabeth W., and Frances J. Milliken. 2000. Organizational silence: a barrier to change and development in a pluralistic world. Academy of Management Review 25 (4): 706-725.

Naquin, Sharon S., and Jennifer Wilson. 2002. Creating competency standards, assessments, and certification. Advances in Developing Human Resources 4 (2): 180-187.

Neill, Stern, Daryl McKee, and Gregory M. Rose. 2007. Developing the organization's sensemaking capability: precursor to an adaptive strategic marketing response. Industrial Marketing Management 36 (6): 731-744.

Nishii, Lisa H. 2013. The benefits of climate for inclusion for gender diverse groups. Academy of Management Journal 56 (6): 1754-1774.

Nishii, Lisa H., Jasmien Khattab, Meir Shemla, and Rebecca Paluch. 2018. A multi-level process model for understanding diversity practice effectiveness. Academy of Management Annals 12 (1): 37-82.

Page, Scott E. 2014. Where diversity comes from and why it matters? European Journal of Social Psychology 44 (4): 267-279.

Pelled, Lisa H. 1996. Demographic diversity, conflict, and work group outcomes: an intervening process theory. Organization Science 7 (6): 615-631.

Pelled, Lisa H., Kathleen M. Eisenhardt, and Katherine R. Xin. 1999. Exploring the black box: an analysis of work group diversity, conflict and performance. Administrative Science Quarterly 44 (1): $1-28$.

Pendry, Louise F., Denise M. Driscoll, and Susannah C. Field. 2007. Diversity training: putting theory into practice. Journal of Occupational and Organizational Psychology 80 (1): 27-50.

Phillips, Katherine W. 2003. The effects of categorically based expectations on minority influence: the importance of congruence. Personality and Social Psychology Bulletin 29 (1): 3-13.

Pless, Nicola, and Thomas Maak. 2004. Building an inclusive diversity culture: principles, processes and practice. Journal of Business Ethics 54 (2): 129-147.

Pregenzer, Arian L. 2014. Evolution and resilience of the nuclear nonproliferation regime. AIP Conference Proceedings-Nuclear Weapon Issues in the 21st Century 1596 (1): 152-159.

Reason, James. 1997. Managing the risks of organizational accidents. Aldershot: Ashgate.

Riolli, Laura, and Victor Savicki. 2003. Information system organisational resilience. Omega: The International Journal of Management Science 31 (3): 227-233.

Roberson, Loriann, Carol T. Kulik, and Molly B. Pepper. 2001. Designing effective diversity training: influence of group composition and trainee experience. Journal of Organizational Behavior 22 (8): 871-885.

Roberson, Loriann, Filomena Buonocore, and Shana M. Yearwood. 2017. Hiring for diversity: the challenges faced by American and European companies in employee selection. In Corporate social responsibility and diversity management, ed. Katrin Hansen and Cathrine Seierstad, 151-171. Cham: Springer.

Robertson, Ivan T., Cary L. Cooper, Mustafa Sarkar, and Thomas Curran. 2015. Resilience training in the workplace from 2003 to 2014: a systematic review. Journal of Occupational and Organizational Psychology 88 (3): 533-562. 
Rosen, Michael. 1991. Coming to terms with the field: understanding and doing organizational ethnography. Journal of Management Studies 28 (1): 1-24.

Rosenkopf, Lori, and Atul Nerkar. 2001. Beyond local search: boundary-spanning, exploration, and impact in the optical disk industry. Strategic Management Journal 22 (4): 287-306.

Salanova, Marisa, Susana Llorens, Eva Cifre, and Isabel Martínez. 2012. We need a hero! Toward a validation of the healthy and resilient organization (HERO) model. Group and Organization Management 37 (6): 785-822.

Salas, Eduardo, Drew Rozell, Brian Mullen, and James E. Driskell. 1999. The effect of team building on performance: an integration. Small Group Research 30 (3): 309-329.

Sarin, Shikhar, and Christopher McDermott. 2003. The effect of team leader characteristics on learning, knowledge application, and performance of cross-functional new product development teams. Decision Sciences 34 (4): 707-739.

Saurin, Tarcisio A., Angela W. Righi, and Éder Henriqson. 2013. Characteristics of complex sociotechnical systems and guidelines for their management: the role of resilience. In Proceedings 5th symposium on resilience engineering, managing trade-offs; 24th-27th June 2013 at Soesterberg, Netherlands, eds. Ivonne Herrera, Jan Maarten C Schraagen, John van der Vorm, and David D. Woods, 11-16. Sophia Antipolis Cedex, France: Resilience Engineering Association.

Sawalha, Ihab H. S. 2015. Managing adversity: understanding some dimensions of organizational resilience. Management Research Review 38 (4): 346-366.

Schippers, Michaéla C., Deanne N. Den Hartog, Paul L. Koopman, and Janique A. Wienk. 2003. Diversity and team outcomes: the moderating effects of outcome interdependence and group longevity and the mediating effect of reflexivity. Journal of Organizational Behavior 24 (6): 779-802.

Seabrooke, Leonard, and Emelie R. Nilsson. 2015. Professional skills in international financial surveillance: assessing change in IMF policy teams. Governance 28 (2): 237-254.

Sheffi, Yossi. 2005. The resilient enterprise: overcoming vulnerability for competitive advantage. Cambridge: MIT Press.

Shen, Jie, Ashok Chanda, Brian D’Netto, and Manjit Monga. 2009. Managing diversity through human resource management: an international perspective and conceptual framework. The International Journal of Human Resource Management 20 (2): 235-251.

Shin, Jiseon, M. Susan Taylor, and Myeong-Gu Seo. 2012. Resources for change: the relationships of organizational inducements and psychological resilience to employees' attitudes and behaviors toward organizational change. Academy of Management Journal 55 (3): 727-748.

Sippola, Aulikki, and Adam Smale. 2007. The global integration of diversity management: a longitudinal case study. The International Journal of Human Resource Management 18 (11): 1895-1916.

Somech, Anit. 2006. The effects of leadership style and team process on performance and innovation in functionally heterogeneous teams. Journal of Management 32 (1): 132-157.

Somers, Scott. 2009. Measuring resilience potential: an adaptive strategy for organizational crisis planning. Journal of Contingencies and Crisis Management 17 (1): 12-23.

Sommer, S. Amy, Jane M. Howell, and Constance N. Hadley. 2016. Keeping positive and building strength: the role of affect and team leadership in developing resilience during an organizational crisis. Group and Organization Management 41 (2): 172-202.

Srikanth, Kannan, Sarah Harvey, and Randall Peterson. 2016. A dynamic perspective on diverse teams: moving from the dual-process model to a dynamic coordination-based model of diverse team performance. Academy of Management Annals 10 (1): 453-493.

Stephens, John P., Emily D. Heaphy, Abraham Carmeli, Gretchen M. Spreitzer, and Jane E. Dutton. 2013. Relationship quality and virtuousness: emotional carrying capacity as a source of individual and team resilience. The Journal of Applied Behavioral Science 49 (1): 13-41.

Sun, Hongyi, Pei-Lee Teh, Karis Ho, and Binshan Lin. 2017. Team diversity, learning, and innovation: a mediation model. Journal of Computer Information Systems 57 (1): 22-30.

Sutcliffe, Kathleen M. 1994. What executives notice: accurate perceptions in top management teams. Academy of Management Journal 37 (5): 1360-1378.

Sutcliffe, Kathleen M., and Timothy J. Vogus. 2003. Organizing for resilience. In Positive organizational scholarship: foundations of a new discipline, ed. Kim S. Cameron, Jane E. Dutton, and Robert E. Quinn, 94-110. San Francisco: Berrett-Koehler Publishers.

Svenson, O. 1979. Process descriptions of decision making. Organizational Behavior and Human Performance 23 (1): 86-112. 
Teixeira, Eduardo Oliveira de, and William B. Werther Jr. 2013. Resilience: continuous renewal of competitive advantages. Business Horizons 56 (3): 333-342

Thompson, Neil. 2016. Anti-discriminatory practice: equality, diversity and social justice, 6th ed. Basingstoke: Palgrave.

Triandis, Harry C. 2003. The future of workforce diversity in international organisations: a commentary. Applied Psychology: an International Review 52 (3): 486-495.

Tsui, Anne S., Terri D. Egan, and Charles A. O’Reilly. 1992. Being different: relational demography and organizational attachment. Administrative Science Quarterly 37 (4): 549-579.

Välikangas, Liisa and Romme, A. Georges L. 2013. How to design for strategic resilience: a case study in retailing. Journal of Organization Design 2 (2): 44-53.

van der Heijden, Beatrice I. J. M., and Norman D. Verhelst. 2002. The psychometric evaluation of a multi-dimensional measurement instrument of professional expertise. Results from a study in small and medium-sized enterprises in the Netherlands. European Journal of Psychological Assessment 18 (2): $165-178$.

van der Vegt, Gerben S., and J. Stuart Bunderson. 2005. Learning and performance in multidisciplinary teams: the importance of collective team identification. Academy of Management Journal 48 (3): 532-547.

van der Vorm, Johan, Dolf van der Beek, Ellen Bos, Niek Steijger, Raphaël Gallis, and Gerard Zwetsloot. 2011. Images of resilience: the resilience analysis grid applicable at several organizational levels? In Proceedings of the fourth resilience engineering symposium, ed. Erik Hollnagel, Eric Rigaud, and Denis Besnard, 263-269. Sophia-Antipolis: Presses des Mines.

van Dick, Rolf, Daan van Knippenberg, Silvia Hägele, Yves R. F. Guillaume, and Felix C. Brodbeck. 2008. Group diversity and group identification: the moderating role of diversity beliefs. Human Relations 61 (10): 1463-1492.

van Knippenberg, Daan, and Julija N. Mell. 2016. Past, present, and potential future of team diversity research: from compositional diversity to emergent diversity. Organizational Behavior and Human Decision Processes 136 (2016): 135-145.

van Knippenberg, Daan, and Michaéla C. Schippers. 2007. Work group diversity. Annual Review of Psychology 58 (2007): 515-541.

van Knippenberg, Daan, Carsten K. W. De Dreu, and Astrid C. Homan. 2004. Work group diversity and group performance: an integrative model and research agenda. Journal of Applied Psychology 89 (6): 1008-1022.

van Knippenberg, Daan, Wendy P. van Ginkel, and Astrid C. Homan. 2013. Diversity mindsets and the performance of diverse teams. Organizational Behavior and Human Decision Processes 121 (2): 183-193.

Varughese, George, and E. Elinor Ostrom. 2001. The contested role of heterogeneity in collective action: some evidence from community forestry in Nepal. World Development 29 (5): 747-765

Vogus, Timothy J., and Kathleen M. Sutcliffe. 2007. Organizational resilience: towards a theory and research agenda. In IEEE International Conference on Systems, Man and Cybernetics, ISIC, 3418-3422. IEEE.

Wagner, Nancy. 2010. IMF performance in the run-up to the financial and economic crisis: Bilateral surveillance in selected IMF member countries (IEO Background Paper No. BP/10/03). Washington: International Monetary Fund.

Walumbwa, Fred O., Suzanne J. Peterson, Bruce J. Avolio, and Chad A. Hartnell. 2010. An investigation of the relationships among leader and follower psychological capital, service climate, and job performance. Personnel Psychology 63 (4): 937-963.

Watson, David, and Auke Tellegen. 1985. Toward a consensual structure of mood. Psychological Bulletin 98 (2): 219-235.

Watson, David, Lee Anna Clark, and Auke Tellegen. 1988. Development and validation of brief measures of positive and negative affect: the PANAS scales. Journal of Personality and Social Psychology 54 (6): 1063-1070.

Watson, Warren E., Kamalesh Kumar, and Larry K. Michaelsen. 1993. Cultural diversity's impact on interaction process and performance: comparing homogeneous and diverse task groups. Academy of Management Journal 36 (3): 590-603.

Weick, Karl E. 1979. The social psychology of organizing. Columbus: McGraw-Hill Humanities.

Weick, Karl E. 1987. Organizational culture as a source of high reliability. California Management Review 29 (2): 112-127. 
Weick, Karl E. 1993. The collapse of sensemaking in organizations: the Mann Gulch disaster. Administrative Science Quarterly 38 (4): 628-652.

Weick, Karl E. 2001. Making sense of the organization. Oxford: Blackwell.

Weick, Karl E., and Kathleen M. Sutcliffe. 2015. Managing the unexpected: sustained performance in a complex world, 3rd ed. Hoboken: Wiley.

Weick, Karl E., Kathleen M. Sutcliffe, and David Obstfeld. 1999. Organizing for high reliability: processes of collective mindfulness. In Research in organizational behaviour, ed. Barry M. Staw and Robert I. Sutton, 81-123. Greenwich: JAI Press.

Weick, Karl E., Kathleen M. Sutcliffe, and David Obstfeld. 2005. Organizing and the process of sensemaking. Organization Science 16 (4): 409-421.

West, Michael A. 2002. Sparkling fountains or stagnant ponds: an integrative model of creativity and innovation implementation in work groups. Applied Psychology 51 (3): 355-387.

Westrum, Ron. 1991. Technologies and society: the shaping of people and things. Belmont: Wadsworth.

Wildavsky, Aaron B. 1991. Searching for safety. New Brunswick: Transaction Books.

Williams, Katherine, and Charles O'Reilly. 1998. Demography and diversity in organizations: a review of 40 years of research. Research in Organizational Behavior 20: 77-140.

Williams, Trenton A., Daniel A. Gruber, Kathleen M. Sutcliffe, Dean A. Shepherd, and Eric Y. Zhao. 2017. Organizational response to adversity: fusing crisis management and resilience research streams. Academy of Management Annals 11 (2): 733-769.

Ybema, Sirek, Dvora Yanow, Harry Wels, and Frans Kamsteeg (eds.). 2009. Organizational ethnography: studying the complexity of everyday life. London: Sage.

$\mathrm{Yu}$, Hui-Chun, and Peter Miller. 2005. Leadership style: the X generation and baby boomers compared in different cultural contexts. Leadership and Organization Development Journal 26 (1): 35-50.

Zoogah, David B., Davina Vora, Orlando Richard, and Mike W. Peng. 2011. Strategic alliance team diversity, coordination, and effectiveness. The International Journal of Human Resource Management 22 (3): 510-529.

Publisher's Note Springer Nature remains neutral with regard to jurisdictional claims in published maps and institutional affiliations. 